\title{
Spatial and Temporal Patterns of Best Management Practice Implementation in the Chesapeake Bay Watershed, 1985-2014
}

Scientific Investigations Report 2018-5171 



\section{Spatial and Temporal Patterns of Best Management Practice Implementation in the Chesapeake Bay Watershed, 1985-2014}

By Andrew J. Sekellick, Olivia H. Devereux, Jennifer L.D. Keisman, Jeffrey S.

Sweeney, and Joel D. Blomquist

Scientific Investigations Report 2018-5171 


\title{
U.S. Department of the Interior \\ DAVID BERNHARDT, Acting Secretary
}

\author{
U.S. Geological Survey \\ James F. Reilly II, Director
}

U.S. Geological Survey, Reston, Virginia: 2019

For more information on the USGS - the Federal source for science about the Earth, its natural and living resources, natural hazards, and the environment-visit https://www.usgs.gov or call 1-888-ASK-USGS.

For an overview of USGS information products, including maps, imagery, and publications,

visit https://store.usgs.gov.

Any use of trade, firm, or product names is for descriptive purposes only and does not imply endorsement by the U.S. Government.

Although this information product, for the most part, is in the public domain, it also may contain copyrighted materials as noted in the text. Permission to reproduce copyrighted items must be secured from the copyright owner.

Suggested citation:

Sekellick, A.J., Devereux, O.H., Keisman, J.L.D., Sweeney, J.S., and Blomquist, J.D., 2019, Spatial and temporal patterns of Best Management Practice implementation in the Chesapeake Bay watershed, 1985-2014: U.S. Geological Survey Scientific Investigations Report 2018-5171, 25 p., https://doi.org/10.3133/sir20185171.

ISSN 2328-0328 (online) 


\section{Acknowledgments}

The authors wish to thank the Chesapeake Bay Program (CBP) for their extensive work compiling Best Management Practice (BMP) information and providing model output in a variety of formats. Lillian Gorman Sanisaca of the U.S. Geological Survey (USGS) assisted in processing data and assembling tables for this report. Andrew LaMotte (USGS) also provided valuable assistance compiling the metadata for this report. 



\section{Contents}

Abstract

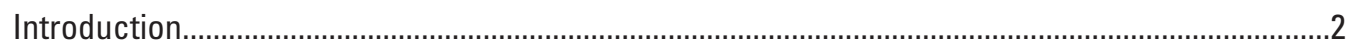

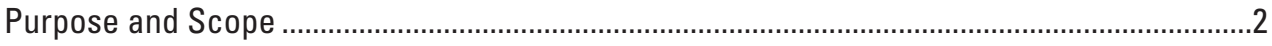

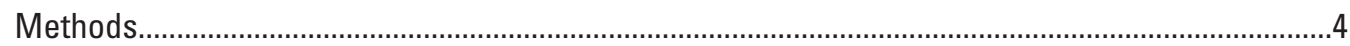

Reporting of Best Management Practice (BMP) Implementation ...........................................4

Estimation of Changes in Nutrient Loads Due to Best Management Practices (BMPs).........6

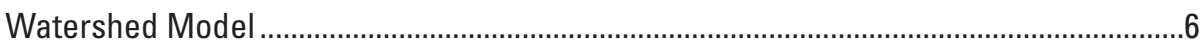

Isolation Scenarios........................................................................................................6

Estimating Load Reduction for Each Best Management Practice (BMP)........................7

Spatial Patterns of Best Management Practice (BMP) Implementation in 2014 ..............................7

Temporal Patterns of Best Management Practice (BMP) Implementation .....................................11

Estimated Effect of Best Management Practices (BMPs) on Nutrient and Sediment Loads.........15

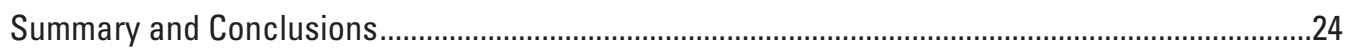

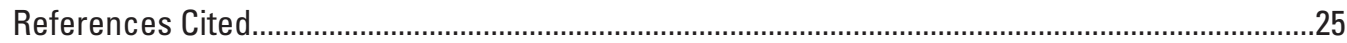




\section{Figures}

1. Map showing chesapeake Bay watershed including River Input Monitoring stations and major watersheds and subregions

2. Maps showing $A$, conservation till, $B$, pasture fencing, and $C$, cover crop implementation intensity in 2014 using reported implementation and land-use information from the Chesapeake Bay Program Phase 5.3.2 model.

3. Maps showing estimated 2014 percent reduction in $A$, total nitrogen, $B$, total phosphorus, and $C$, total sediment due to Best Management Practices in the Chesapeake Bay watershed.

4. Graphs showing estimated $A$, total nitrogen load, $B$, total phosphorus load, and $C$, total sediment load from 1985 through 2014 for the No Action scenarios, which do not include Best Management Practices, and the Progress scenarios, which do include BMPs

5. Graphs showing estimated reduction in $A$, total nitrogen load, $B$, total phosphorus load, and $C$, total sediment load due to Best Management Practices from 1985 through 2014

6. Graphs showing estimated $A$, total nitrogen reduction, $B$, total phosphorus reduction, and $C$, total sediment reduction by Best Management Practice category on agricultural lands in 2014

7. Graphs showing estimated $A$, total nitrogen reduction, $B$, total phosphorus reduction, and $C$, total sediment reduction by Best Management Practice category on developed lands in 2014

8. Graphs showing estimated $A$, total nitrogen reduction, $B$, total phosphorus reduction, and $C$, total sediment reduction from agricultural Best Management Practices from 1985 through 2014 in the Chesapeake Bay watershed

9. Graphs showing estimated $A$, total nitrogen reduction, $B$, total phosphorus reduction, and $C$, total sediment reduction from developed land Best Management Practices from 1985 through 2014 in the Chesapeake Bay watershed 


\section{Tables}

1. List of Best Management Practice categories evaluated in model....................................5

2. Estimated reduction of nutrients to streams due to Best Management Practices and land use in Chesapeake Bay watershed subregions in 2014 ....................8

3. Implementation of Best Management Practices in the Chesapeake Bay watershed in 2014

4. Estimated reduction of nutrients to streams in Chesapeake Bay watershed subregions due to Best Management Practices in 2005 and 2014 using Progress and No Action Chesapeake Bay Program Phase 5.3.2 model scenarios.........14

5. Agricultural land Best Management Practice estimated mass reduction per unit of implementation in the Chesapeake Bay watershed

6. Developed land Best Management Practice estimated mass reduction per unit of implementation in the Chesapeake Bay watershed.

\section{Conversion Factors}

\begin{tabular}{lcl}
\hline \multicolumn{1}{c}{ Multiply } & By & \multicolumn{1}{c}{ To obtain } \\
\hline foot $(\mathrm{ft})$ & Length & meter $(\mathrm{m})$ \\
\hline & 0.3048 & \\
\hline acre & Area & square meter $\left(\mathrm{m}^{2}\right)$ \\
\hline & 4,047 & \\
\hline pound, avoirdupois $(\mathrm{lb})$ & Mass & metric ton \\
pound, avoirdupois $(\mathrm{lb})$ & 0.00045359 & kilogram $(\mathrm{kg})$ \\
pound per cubic foot $\left(\mathrm{lb} / \mathrm{ft}^{3}\right)$ & 0.4536 & gram per cubic centimeter $\left(\mathrm{g} / \mathrm{cm}^{3}\right)$ \\
\hline
\end{tabular}

Temperature in degrees Celsius $\left({ }^{\circ} \mathrm{C}\right)$ may be converted to degrees Fahrenheit $\left({ }^{\circ} \mathrm{F}\right)$ as follows:

$$
{ }^{\circ} \mathrm{F}=\left(1.8 \times{ }^{\circ} \mathrm{C}\right)+32 .
$$

Temperature in degrees Fahrenheit $\left({ }^{\circ} \mathrm{F}\right)$ may be converted to degrees Celsius $\left({ }^{\circ} \mathrm{C}\right)$ as follows:

$$
{ }^{\circ} \mathrm{C}=\left({ }^{\circ} \mathrm{F}-32\right) / 1.8 \text {. }
$$

\section{Datum}

Horizontal coordinate information is referenced to the North American Datum of 1983 (NAD 83). 



\title{
Spatial and Temporal Patterns of Best Management Practice Implementation in the Chesapeake Bay Watershed, 1985-2014
}

\author{
By Andrew J. Sekellick, Olivia H. Devereux², Jennifer L.D. Keisman', Jeffrey S. Sweeney³, \\ and Joel D. Blomquist ${ }^{1}$
}

\section{Abstract}

Efforts to restore water quality in Chesapeake Bay and its tributaries often include extensive Best Management Practice (BMP) implementation on agricultural and developed lands. These BMPs include a variety of methods to reduce nutrient and sediment loads, such as cover crops, conservation tillage, urban filtering systems, and other practices.

Estimates of BMP implementation throughout the Chesapeake Bay watershed were provided for each year from 1985 through 2014 by the Chesapeake Bay Program (CBP). This dataset of BMP implementation is a compilation of actions reported by New York, Maryland, Pennsylvania, Delaware, West Virginia, Virginia, and the District of Columbia, and includes a wide array of management activities. Management actions vary among the jurisdictions and generally reflect the typical land use in each region.

The amount of implementation also varies according to different priorities, reporting practices, and special programs within each jurisdiction. For example, extensive cover crop implementation was reported in Maryland whereas Pennsylvania, in general, has lower levels of BMP implementation reported on cropland. Pennsylvania and Maryland have higher levels of infiltration BMPs on developed land compared to those in Virginia.

Conservation tillage BMPs accounted for the majority of reported agricultural BMP implementation in 1985. By 2014, however, a more diverse collection of agricultural BMPs was reported and conservation tillage BMPs accounted for a smaller proportion of overall reported agricultural BMP implementation. After the year 2000, land-use change BMPs, such as land retirement, pasture fencing, and forest buffers, were more commonly reported across the Chesapeake Bay watershed.
Expected changes in nutrient and sediment loads in the Chesapeake Bay watershed due to BMP implementation were estimated by use of specially designed annual scenarios of the CBP Partnership Phase 5.3.2 Watershed Model. Nitrogen loads to streams were estimated to be reduced by 11 percent from 1985 to 2014 due to the implementation of BMPs. Compared with 1985, phosphorus loads were estimated to be 19 percent lower and sediment loads were estimated to be 23 percent lower by 2014 due to the effects of BMPs.

Reductions in total nitrogen from 1985 to 2014 due to BMPs varied spatially across the watershed and were estimated to be as high as 42 percent in areas of the Eastern Shore of the Chesapeake Bay. Reductions in phosphorus and sediment also varied spatially, with the largest reductions occurring in the Potomac watershed upstream of Washington, D.C. and the Eastern Shore of Maryland, according to the CBP model results.

Additional model scenarios were developed to estimate the effect of individual BMP types. The largest estimated reductions in total nitrogen loads on agricultural lands in 2014 were attributed to land retirement, animal waste management systems, and conservation tillage. The largest estimated reductions in total phosphorus loads on agricultural lands were attributed to animal waste management systems, pasture fencing, and phytase feed additives in 2014. The largest estimated reduction in total sediment loads on agricultural lands was attributed to conservation tillage, pasture fencing, and conservation plans.

Dry ponds, wet ponds, and constructed wetlands were reported extensively throughout the watershed. These BMPs accounted for about half of the reduction in nitrogen loads from developed land to streams, half of the phosphorus reduction, and about a third of the sediment reduction.

\footnotetext{
${ }^{1}$ U.S. Geological Survey

${ }^{2}$ Devereux Environmental Consulting, Inc.

${ }^{3}$ U.S. Environmental Protection Agency
} 


\section{Introduction}

Chesapeake Bay is the largest estuary in North America and a valuable ecological and economic resource. Anthropogenic pressures, including increased urbanization and more intensive agricultural production, have led to degraded water quality conditions throughout the watershed (Phillips, 2007). The U.S. Environmental Protection Agency (EPA) has classified Chesapeake Bay as "impaired" by sediment and nutrients, and implemented Total Maximum Daily Loads (TMDLs) for nitrogen, phosphorus, and sediment (U.S. Environmental Protection Agency, 2010a).

A variety of best management practices (BMPs) are often used to mitigate nutrient and sediment loadings in order to meet the TMDL regulatory requirements. These Best Management Practices (BMPs) are an important part of Chesapeake Bay restoration efforts; however, further information to quantify their effects on nutrient and sediment loads is/will be required to improve the targeting of management actions across the watershed. Whereas field-scale assessments of BMP effectiveness exist, few regional-scale estimates of the effects of BMPs on nitrogen, phosphorus, and sediment loads delivered to streams are available (Liu and others, 2017).

The seven major jurisdictions in the Chesapeake Bay report BMP implementation to the Chesapeake Bay Program (CBP) annually. The major jurisdictions are New York, Maryland, Pennsylvania, Delaware, West Virginia, Virginia, and the District of Columbia (fig. 1). The CBP has agreed upon a set of BMPs that are considered effective for reducing nitrogen, phosphorus, and sediment loads. The CBP and the U.S. Geological Survey (USGS) have collaborated to develop a deterministic model (the Phase 5.3.2 Watershed Model) to quantify how water quality in the Chesapeake Bay watershed responds to changes in watershed and airshed management actions as well as changes in nutrient sources and other factors (U.S. Environmental Protection Agency, 2010b).

The effectiveness of BMPs and individual BMP types has not been extensively studied or quantified in the Chesapeake Bay watershed. The evaluation of BMP implementation data, including the spatial locations, temporal patterns, and their modeled effects on nitrogen, phosphorus and sediment that is delivered to streams, provide much needed insight on the effectiveness of management strategies. The USGS has collaborated with the CBP to assess the amount of BMP implementation over time and estimate the changes in water quality attributable to these management actions.

\section{Purpose and Scope}

This report describes the spatial and temporal patterns of BMP implementation across the Chesapeake Bay watershed from 1985 through 2014. Methods to estimate the effect of BMP implementation on nitrogen, phosphorus, and sediment loads also are described. Additionally, the effect of individual BMP types on nutrient loads is estimated.

The CBP selected 2017 as a midpoint assessment of the TMDLs. The TMDLs were designed to have all jurisdictions implement reduction strategies by 2025 , so that the bay will attain its water-quality goals. The midpoint assessment period was designated to assess progress in meeting reduction strategy goals and to evaluate recent science that may indicate necessary changes to those strategies (U.S. Environmental Protection Agency, 2010a).

A companion dataset to this report is available at (https:// doi.org/10.5066/P9OVU9PX) and includes detailed descriptions of BMP types as well as tables of model output at a selection of spatial scales (Devereux and others, 2018). 


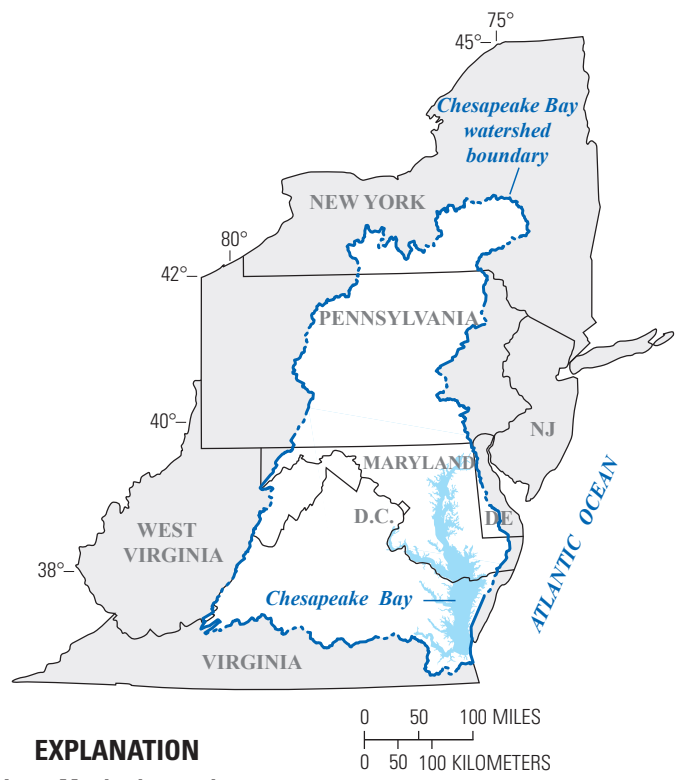

River Input Monitoring stations

(1) Susquehanna River at Conowingo, MD

(2) Potomac River at Chain Bridge, DC

(3) James River at Cartersville, VA

(4) Rappahannock River near Fredericksburg, VA

(5) Appomattox River near Matoaca, VA

6) Pamunkey River near Hanover, VA

(7) Mattaponi River near Beulahville, VA

(8) Patuxent River near Bowie, MD

(9) Choptank River near Greensboro, MD

Major watersheds and subregions

\begin{tabular}{|l|l}
\hline Appomattox \\
Choptank \\
James \\
Mattaponi \\
Pamunkey \\
Patuxent \\
Potomac \\
Rappahannock \\
Susquehanna \\
Eastern Shore \\
Western Shore
\end{tabular}

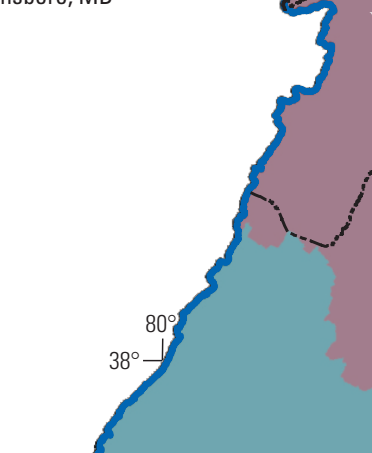




\section{Methods}

\section{Reporting of Best Management Practice (BMP) Implementation}

The seven major jurisdictions in the Chesapeake Bay watershed (New York, Maryland, Pennsylvania, Delaware, West Virginia, Virginia, and the District of Columbia) began reporting estimates of BMP implementation to the CBP in the late 1990s, and have provided estimates of all BMP implementation for each year from 1985 through 2014. CBP BMP data include State and Federally funded implementation data as well as practices funded by non-governmental organizations and voluntary implementation (Hively and others, 2013). The reporting for each year consists of all BMPs in the Chesapeake Bay watershed that were considered effective for that year, including active BMPs that have been installed in prior years. Structural BMPs, like animal waste management systems, can reduce pollutant runoff for many years. Other BMPs, like urban filtering practices, must be inspected and maintained each year to be effective (U.S. Environmental Protection Agency, 2010b). Approximately 150 different types of BMPs were reported in 2014. For this report, the CBP provided BMP implementation data that were submitted by jurisdictions for assessment using the Phase 5.3.2 Watershed Model. The data were from annual scenarios for 1985 through 2014.

The various BMP types were grouped into 55 BMP categories for evaluation, and included BMPs for both agricultural and developed land (table 1). The categories were determined by the similarity of the BMPs. For example, there are approximately 100 different types of agricultural cover crops that represent various planting dates, planting methods, and crop types (U.S. Environmental Protection Agency, 2010b). Planting dates are early, standard, or late, and reflect the planting time in relation to the first killing frost. The timing affects the successful establishment of the crop. The planting methods include drilled, aerial, or other, and can affect how well the seeds germinate. Cover crop types include various varieties such as rye, wheat, tillage radish, and many more. The various types of cover crops are presumed to have a similar effect on water quality in the Phase 5.3.2 Watershed Model. For the purposes of this report and the analysis methods used, evaluating each cover crop type individually did not result in an improved understanding of BMP implementation trends or their effects on water quality. The types of cover crops reported vary in large part by each state's ability to track that level of detail. All cover crops were therefore grouped into a single category to more clearly evaluate their expected effect on nutrient and sediment loads to streams. Similar grouping occurred for several other agricultural and developed BMPs.
BMPs were reported at multiple spatial scales including counties, watersheds, and states. The jurisdictions have different reporting methods and are not necessarily consistent among states, BMPs, or reporting years. The CBP compiles most of the annual reported BMP implementation at the landriver segment modeling unit (average size 26.2 square miles) that is used in the CBP Partnership Phase 5.3.2 Watershed Model (U.S. Environmental Protection Agency, 2010b). Animal data in the CBP model originates from the U.S. Department of Agriculture, National Agricultural Statistics Service and is only available at the county scale. Therefore, the BMPs that impact manure nutrients, such as animal feed additives or animal waste management systems, are compiled at the county scale. Depending on the type of BMP, implementation may be reported in a variety of units, including acres, animal units (1,000 pounds of live animal), feet, or pounds.

The CBP BMP data require careful interpretation. In some major jurisdictions, there are BMPs with large shifts in the levels of reported implementation from year to year. These can reflect changes in reporting standards rather than changes in the actual practice implementation. Changes in reporting occur as the jurisdictions change their tracking systems, improve their understanding of the BMP functions in the context of the modeling system, and as the BMPs themselves are re-evaluated and re-defined. In addition, the establishment of the Chesapeake Bay TMDL in 2010 resulted in a revision of reported BMP implementation from 2006 by the jurisdictions in the Chesapeake Bay watershed (Wastewater Technical Workgroup, 2013). An increase in reported implementation from 2006 to 2014 may be a result of revised interpretation of historical records in addition to increased implementation. Although changes in reporting standards and evaluating processes have occurred during the multi-year compilation of the CBP BMP data, the dataset is thorough and extensive, and can be used to estimate the effect of BMPs on water quality.

All BMPs types are periodically reevaluated by the CBP Partnership expert panels, which can result in changing names and definitions. For this analysis, all BMP implementation types were related to the closest equivalent of the 2014 BMP definitions. For example, the nutrient management BMPs used in this analysis are the efficiency versions of Tier 1, enhanced, and decision nutrient management BMPs (U.S. Environmental Protection Agency, 2010b).

An estimate of the intensity of BMP implementation for the year 2014 for each land-river modeling segment was calculated by dividing the amount of reported implementation of selected BMPs as reported in the Phase 5.3.2 Watershed Model by the available land acres of the relevant land use. For example, acres of cover-crop implementation were divided by acres of cropland, and acres of pasture fencing were divided by acres of pasture land. 
Table 1. List of Best Management Practice (BMP) categories evaluated in model.

\section{Agricultural land BMPs}

\begin{tabular}{|c|c|}
\hline Alternative crops & Abandoned mineland reclamation \\
\hline Alum & Bio-retention \\
\hline Animal waste management systems & Bio-swales \\
\hline Barnyard runoff control & Combined sewer overflow connections \\
\hline Commodity cover crops & Dry ponds \\
\hline Conservation plans & Erosion and sediment controls \\
\hline Conservation tillage & Filtering practices \\
\hline Cover crops & Forest buffers \\
\hline Dairy precision feeding & Forest Conservation Act \\
\hline Dirt and gravel roads & Impervious surface reduction \\
\hline Enhanced nutrient management & Infiltration \\
\hline Forest buffers & Permeable pavement \\
\hline Grass buffers & Retrofit stormwater management \\
\hline High residue tillage & Shoreline management \\
\hline Horse pasture management & Stream restoration \\
\hline Land retirement & Street sweeping \\
\hline Loafing lot management & Stormwater management-era 02 to 10 \\
\hline Manure transport & Stormwater management - era 85 to 02 \\
\hline Mortality composting & Tree planting \\
\hline Off stream watering, without fences & Urban nutrient management commercial applicators \\
\hline Pasture fencing & Urban nutrient management, do-it-yourself \\
\hline Phytase feed additive & Urban nutrient management plan \\
\hline Precision agriculture & Vegetative open channels \\
\hline Precision rotational grazing & Wet pond/wetland \\
\hline
\end{tabular}

Stream restoration

Streamside forest buffers

Streamside grass buffers

Tier 1 nutrient management

Tree planting

Water control structures

Wetland restoration 


\section{Estimation of Changes in Nutrient Loads Due to Best Management Practices (BMPs)}

\section{Watershed Model}

The CBP Partnership Phase 5.3.2 Watershed Model was used to evaluate the effects of BMPs on water quality. The model, in part, assists CBP decision-makers in estimating the collective actions needed to achieve State and Federal waterquality standards necessary to restore the health of Chesapeake Bay. The model is built through community and participatory input and used for decision-support purposes by the jurisdictions in the Chesapeake Bay watershed. It is designed to address questions of how Chesapeake Bay water quality will respond to changes in watershed and airshed management actions (U.S. Environmental Protection Agency 2010b).

The CBP model can provide estimates of nitrogen, phosphorus, and sediment stream loads generated from sources such as manure, fertilizer, atmospheric deposition, wastewater, and urban areas. Other factors included in the model can determine the amount of each source that is transported to streams. These input variables were mostly estimated at the land-river segment scale, but county-level estimates based on compilations of available data also were used. The model generates annual estimates of nutrient and sediment loads at the landriver segment spatial scale for the years from 1985 to 2014 . For this report, loads were summed from these smaller units to 11 geographic regions across the Chesapeake Bay watershed. These include the watersheds for the nine River Input Modeling (RIM) stations and areas on the Eastern and Western Shore of Chesapeake Bay downstream from the RIM stations (fig. 1). The estimated loads used in this report are considered edgeof-stream and do not include in-stream processing or decay during movement to tidal waters. Edge-of-stream is defined as the edge of a large stream, typically a fourth-order stream, for a total of about a thousand stream segments in the model (U.S. Environmental Protection Agency, 2010b). This is determined for each stream based on streamflow and the distance to a monitoring station.

A variety of factors, such as groundwater lag times and other response lags, may not be fully represented in yearly model predictions. The model is intended to provide quantitative measures of progress in achieving water-quality goals in the distant future using the most complete dataset of reported BMP implementation available for the region described in this report. Furthermore, the wide variety of BMP actions may result in varied model accuracy due to the different modes of action of each BMP type and the interaction of soil type, geology, precipitation, maintenance, and other factors. The model may be a better predictor of the effect of one BMP type compared to another BMP type (U.S. Environmental Protection Agency, 2010b).

The estimated effect of BMPs on nutrients and sediment were modeled as a nonlinear cascading system (U.S. Environmental Protection Agency, 2010b). There were no predetermined nitrogen, phosphorus, or sediment reductions for each BMP in all situations. The amount of nutrient and sediment reduction per unit of BMP is contingent on the land use it is applied to, other BMPs used in the area, and additional factors such as the amount of nutrient inputs on the land surface. Although there are effectiveness values for most of the BMPs in the CBP model, the total effect of BMPs cannot be calculated with these values alone. The model output can also be used to estimate the total summed effect of all load reductions from all BMPs by each land-use category.

The CBP model can be run for a variety of scenarios. For this study, "Progress" scenarios, representing an estimate of watershed conditions and all reported BMP implementation, were run for each year from 1985 to 2014. "Baseline" scenarios, also referred to as "No Action" scenarios, were also run for each year from 1985 to 2014. All of the conditions in the yearly No Action scenarios are the same as those in the corresponding yearly Progress scenarios, however, BMPs are excluded. This ensures that the full estimated effect of all BMPs on nitrogen, phosphorus, and sediment for each year from 1985 to 2014 can be calculated by subtracting the loads from the No Action scenario model results from the Progress scenario model results. A prediction of atmospheric deposition of nitrogen for the year 2025 (the target date for full TMDL implementation) was used for all scenarios to remove the effects of changing air quality from the study (U.S. Environmental Protection Agency, 2010a).

\section{Isolation Scenarios}

In addition to the yearly Progress and No Action scenarios, a set of 35 isolation model scenarios was designed to run in series to isolate the effect of individual BMPs reported in the 2014 Progress Review. The order and design of the isolation scenarios were consistent with the way that BMPs are credited by the CBP in the Phase 5.3.2 Watershed Model, and could not be generalized to other models where BMPs are credited differently. Each scenario builds on the next following the logic used in crediting the BMPs.

To ensure that the BMP effects were isolated, it was necessary to assume identical initial conditions for all other variables in a scenario. Initial conditions from the 2014 Progress scenario of the CBP model were used and include, in part, 2014 model year land use, 2014 model year number of animals, and 2014 model year number of septic systems. The 2014 model year land use is an estimate based on a projection of historical land-use data. The historical land uses were developed primarily from remote sensing data and Census of Agriculture information, and included changes to land use that resulted from BMPs, such as forest buffers and changes due to development (U.S. Environmental Protection Agency, 2010b).

The baseline isolation scenario does not have any BMPs active in the model and is identical to the No Action scenario. Subsequent scenarios add the various land-use change BMPs to the baseline scenario whereas all prior BMPs are kept in the subsequent scenario. Thus, the last one in the sequence has 
all land-use change BMPs included. Scenarios including feed additive BMPs and manure transport were added to the scenario with all land-use change BMPs following the sequence in the scenario list. The final scenario has all the land-use change BMPs, agricultural load reduction BMPs, and manure transport included.

BMPs that utilize reduction efficiencies or direct load reductions in the model were added individually to the scenario with the land-use change BMPs, animal BMPs, and manure transport. Each scenario has one efficiency or load reduction BMP in addition to the land-use change BMPs, animal BMPs, and manure transport. A BMP that affects developed land uses can be used in the same scenario as another BMP that affects agricultural land uses because neither BMP affects the land-use loads for the other BMP in that scenario.

\section{Estimating Load Reduction for Each Best Management Practice (BMP)}

The results from the isolation scenarios provided an estimated nutrient and sediment load reduction for each BMP in all of the 11 different geographic regions described earlier as well as the entire Chesapeake Bay watershed. These estimated reductions were the effect of individual BMP types run in specific scenarios, and cannot directly be used to determine the impact on water quality in a stream. Instead, the percent reduction by BMP in nutrient and sediment loads is used to estimate the expected reduction on agricultural or developed land. For each land-use sector, the percent reduction from a BMP from the isolation scenarios is multiplied by the total combined effect of BMPs from the Progress and No Action scenarios. This value can then be divided by the total amount of implementation for an estimate of pounds of nitrogen, phosphorus, or sediment reduced per unit of BMP implemented:

$$
d=(a * b) / c
$$

where

$$
\begin{aligned}
& d \quad \text { is estimate of reduction in nutrient } \\
& \text { and sediment load per unit of BMP } \\
& \text { implementation; } \\
& \text { a percent reduction for each BMP by sector } \\
& \text { as determined from the } 2014 \text { isolation } \\
& \text { scenarios; } \\
& \text { is total estimated load reduction from BMPs } \\
& \text { for a sector as calculated from the No } \\
& \text { Action and Progress scenarios for the } 2014 \\
& \text { model year; and } \\
& \text { is amount of implementation credited for each } \\
& \text { BMP (acres, animal units, feet, or pounds) } \\
& \text { for the 2014 model year. }
\end{aligned}
$$

The estimate of reduction load per unit of implementation was developed using the 2014 model year. To determine the expected effect of each BMP type for each year from 1985 to
2014 , this value was multiplied by the amount of implementation and normalized by the total estimated reduction from BMPs by sector from the No Action and Progress scenarios for the same year.

This logic was consistent as long as BMPs in earlier years were also included in the 2014 Progress scenario, and the mix of BMPs and relative amount of BMPs to each other remains similar to the 2014 Progress scenario. A future implementation plan with several types of innovative practices and programs may not meet these criteria as there may be BMP types and interactions between them that can't be accounted for with this method.

\section{Spatial Patterns of Best Management Practice (BMP) Implementation in 2014}

The Potomac River subregion, defined in this report as the watershed upstream of the USGS streamgage at Chain Bridge (fig. 1, site 2), makes up 18 percent of the total area in the Chesapeake Bay watershed and accounts for 32 percent of the total nitrogen reduction due to agricultural BMPs, 38 percent of the phosphorus reduction due to agricultural BMPs, and 30 percent of the sediment reduction due to agricultural BMPs (table 2). Approximately 19 percent of the total crop area, 36 percent of the total pasture area, and 27 percent of the total animal feeding operation areas of the Chesapeake Bay watershed are in the Potomac subregion. In contrast, the James River subregion makes up 10 percent of the total area in the Chesapeake Bay watershed and accounts for only 2 percent of the total agricultural nitrogen reduction due to BMPs, 6 percent of the phosphorus reduction, and 15 percent of the sediment reduction. In general, the remaining subregions were estimated to have a share of the total reductions in nutrient loads due to BMPs that are similar to their share of land area in the watershed.

The BMPs with the most reported acres of implementation in the Chesapeake Bay watershed in 2014 were conservation plans, conservation tillage, and tier 1 nutrient management plans (table 3 ). These three BMPs totaled nearly $8,000,000$ acres of implementation across the watershed and accounted for roughly two-thirds of agricultural BMP implementation. BMP implementation varied spatially across the watershed, however. BMP implementation generally reflected the typical land use in different regions. Implementation of BMPs designed to reduce nutrient and sediment loads from animal production were more often reported in areas with larger numbers of animal-based agriculture. A high intensity of conservation tillage is located on the Eastern and Western Shore of Chesapeake Bay as well as along parts of the Susquehanna River (fig. 2A). The Potomac subregion, which has a large amount of animal production, accounts for 42 percent of all pasture fencing BMP implementation (fig. $2 B$ ). Higher amounts of cover crops were reported in farmland throughout 


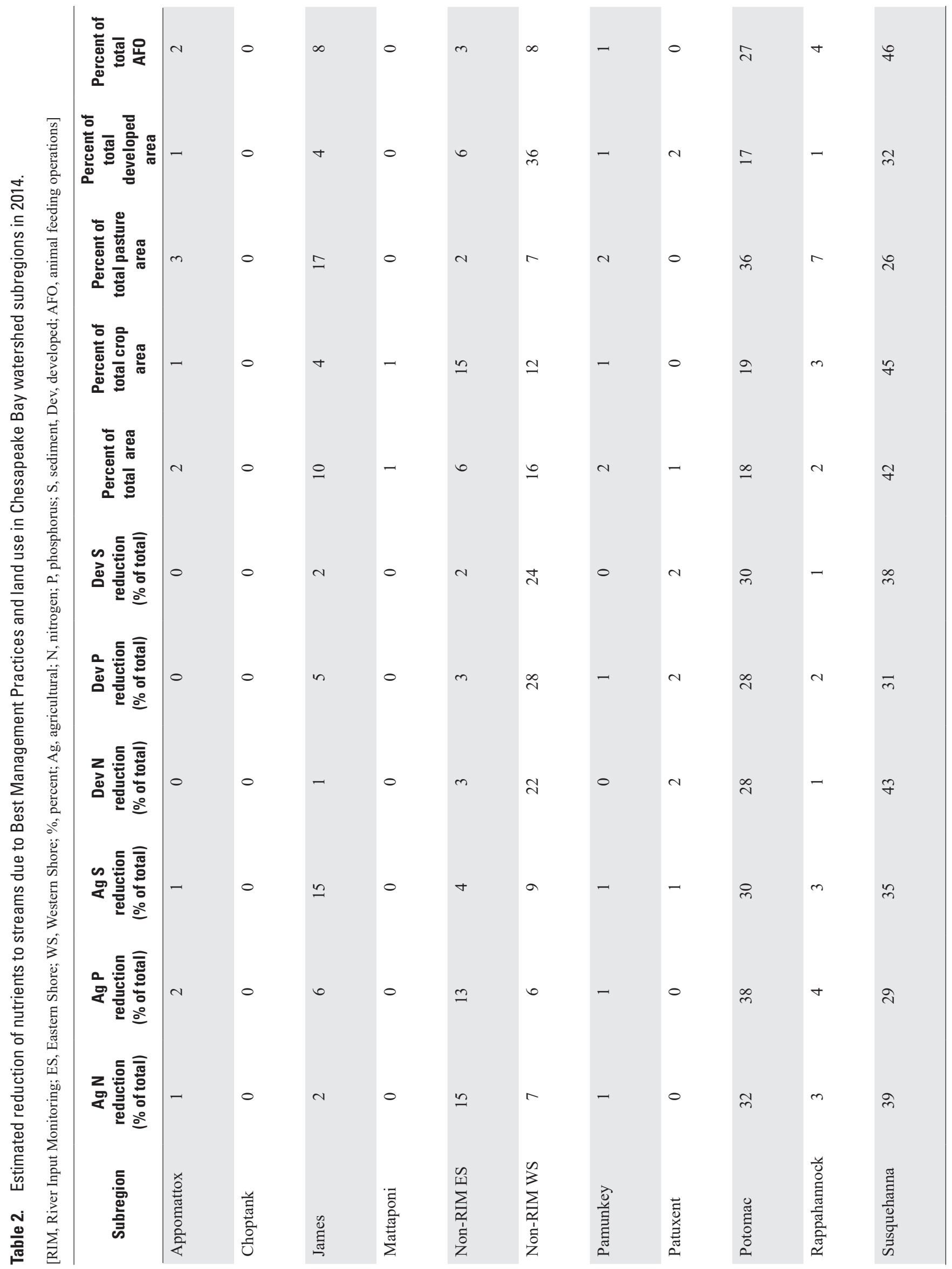


Table 3. Implementation of Best Management Practices (BMPs) in the Chesapeake Bay watershed in 2014.

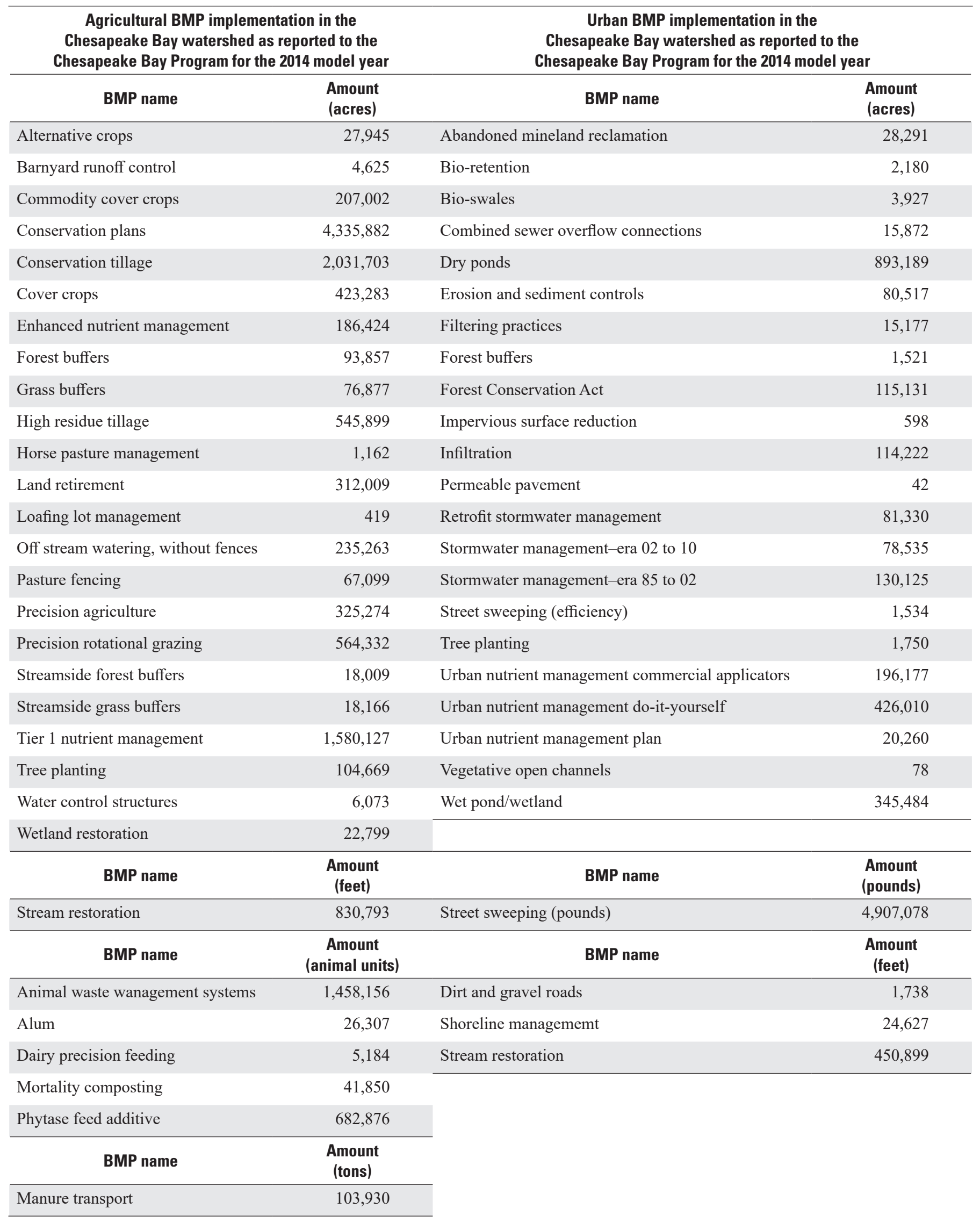




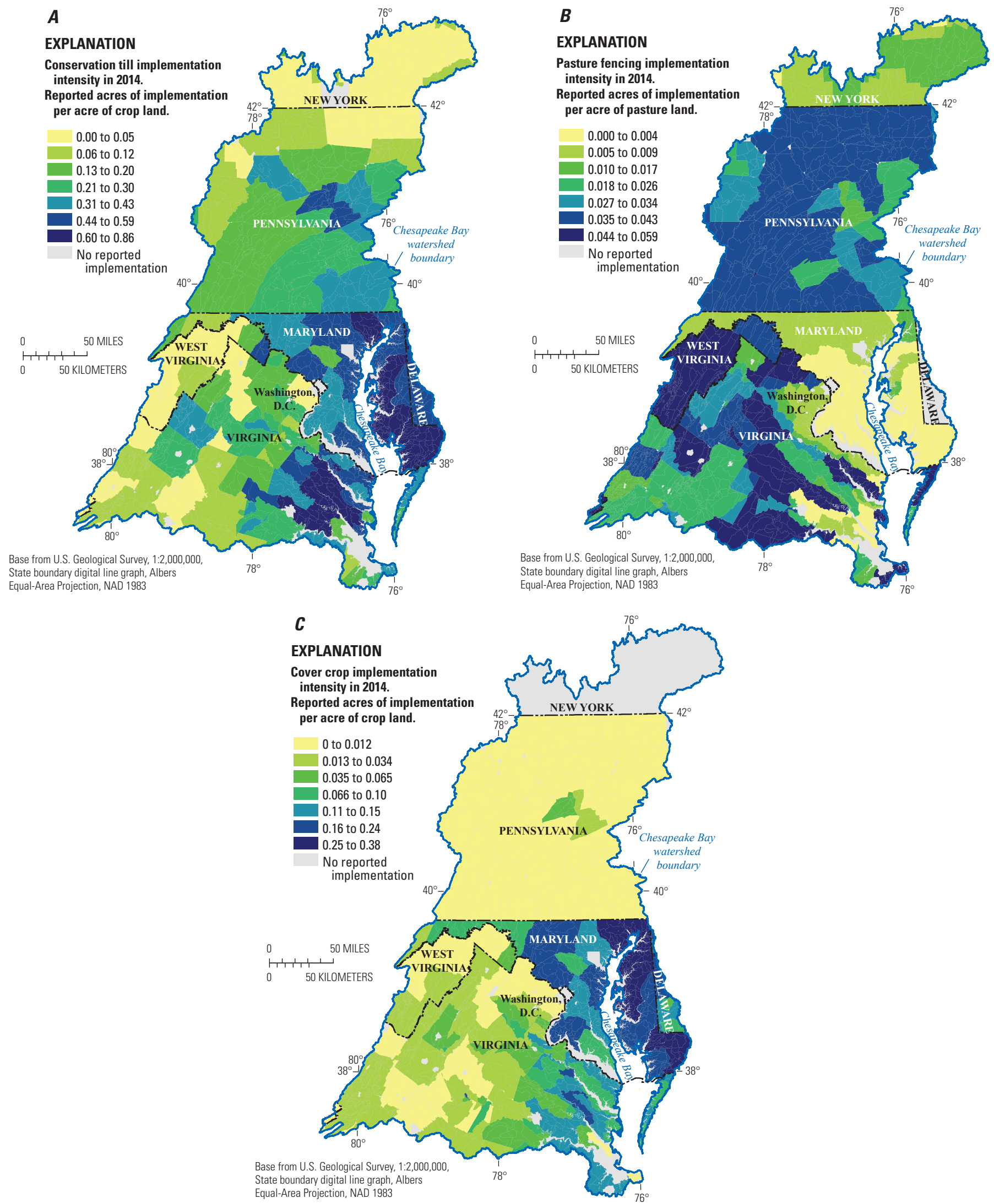

Figure 2. A, conservation till, $B$, pasture fencing, and $C$, cover crop implementation intensity in 2014 using reported implementation and land-use information from the Chesapeake Bay Program Phase 5.3.2 model. 
the state of Maryland than in Virginia, Pennsylvania, and Delaware (fig. 2C).

Spatial patterns in reported implementation also can be identified at the jurisdictional level. These can reflect the priorities of the jurisdiction, different reporting practices, or special programs. Extensive cover crop implementation was reported in Maryland; approximately 71 percent of 423,283 reported cover crop acres were in Maryland (fig. 2C). Pennsylvania, in general, had limited reporting of BMP implementation on cropland. Although it accounts for approximately 41 percent of the crop area in the watershed, only 33 percent of the conservation tillage, 35 percent of the conservation plan, and 22 percent of the tier 1 nutrient management plan BMPs were reported in the State. Twenty-three percent of reported pasture fencing BMPs were in Pennsylvania, which had 20 percent of the pasture land use in the Chesapeake Bay watershed.

The CBP Phase 5.3.2 Watershed Model estimated up to a 42-percent reduction in total nitrogen to streams due to all BMPs across parts of the Eastern Shore of Chesapeake Bay in 2014 (fig. 3A). Total phosphorus and total sediment loads were estimated to be reduced by up to 85 percent by BMPs in 2014 . In general, the largest reductions in nutrient and sediment loads were predicted on the Eastern Shore of Chesapeake Bay and in parts of Virginia and West Virginia. Nutrient and sediment loads in areas of the watershed that have large amounts of forest land use were not predicted to have reductions of more than 5 percent (figs. $3 B$ and $3 C$ ). These areas were estimated to have relatively low loading rates in comparison to the rest of the watershed.

\section{Temporal Patterns of Best Management Practice (BMP) Implementation}

Overall, reported BMP implementation has changed substantially from 1985 to 2014. Agricultural BMPs reported as acres in the Chesapeake Bay watershed increased by approximately 425 percent from 1985 to 2014 and 72 percent from 2000 to 2014. Reported animal type BMPs increased by 52 percent from 2000 to 2014. Only a small number of animal type BMPs were reported to be implemented in 1985. Acres of BMPs reported on developed land increased by 206 percent from 2000 to 2014. Few developed land BMPs were reported in 1985.

Implementation of BMPs from 1985 to 2014 has varied in different ways for each BMP type. Conservation tillage BMPs accounted for the majority of agricultural BMPs in 1985 and reported implementation increased by approximately 1 percent from 1985 to 2014, however, they made up a much smaller proportion of the overall agricultural BMP implementation reported in 2014. Eighty-eight percent of the acres of agricultural BMPs reported in 1985 were conservation tillage practices. This number decreased to 26 percent by 2000 and to 18 percent by 2014. A larger proportion of reported agricultural BMP implementation after the year 2000 consisted of land-use change type BMPs such as land retirement, pasture fencing, and forest buffers. Reporting of pasture fencing increased from 4,830 acres in 2000 to 67,099 acres in 2014. These BMPs were generally reported in small quantities or not at all prior to 2000 .

Reported acres of tier 1 nutrient management plan BMPs decreased sharply after 2009 , decreasing by 55 percent by 2014 (Devereux and others, 2018). This may not have been caused by a decrease in actual implementation; consistent reporting standards for this BMP were not available throughout the entire time period (U.S. Environmental Protection Agency, 2010b). The actual level of implementation may be more accurately represented during these later years.

The results of the No Action and Progress scenarios of the CBP Phase 5.3.2 Watershed Model provided an estimate of the yearly nitrogen, phosphorus, and sediment load reduction due to BMPs on agricultural and developed lands from 1985 to 2014. Changes in land use, nutrient input changes not related to BMPs, and wastewater-treatment improvements were represented in the 8-percent reduction in nitrogen loads to streams in the Chesapeake Bay watershed from 1985 to 2014 in the No Action scenarios. The 2014 Progress scenario was predicted to be 11 percent lower than the 2014 No Action scenario, indicating that an estimated 11-percent reduction in nitrogen loads to streams could be attributed due to the implementation of BMPs through 2014 (fig. 4A). Phosphorus loads to streams from 1985 to 2014 were estimated to have decreased by 21 percent due to land-use changes, nutrient input changes not related to BMPs, and wastewater treatments, with an additional 19-percent reduction in phosphorus estimated due to the implementation of BMPs (fig. 4B). Land-use changes during this period were estimated to account for about 1 percent of the reduction in sediment loads, with a further reduction of 23 percent estimated from BMPs (fig. 4C). In 2005, BMPs were estimated to have reduced total nitrogen loads by 8 percent, total phosphorus loads by 10 percent, and total sediment loads by 16 percent, respectively, across the Chesapeake Bay watershed.

BMPs were estimated to have reduced nutrient and sediment loads to streams by a larger amount through 2014 than through 2005 in all subregions of the Chesapeake Bay watershed using the No Action and Progress scenarios (table 4). In some subregions, such as the Susquehanna, the change in estimated reductions between 2005 and 2014 were more pronounced than others where estimated improvements were minimal. Nitrogen loads in the Eastern Shore subregion were estimated to have been reduced 18 percent through 2005 and 25 percent through 2014, representing a substantial increase in BMP implementation. In comparison, nitrogen loads to streams in the Susquehanna subregion were estimated to be reduced by 8 percent through 2005 and 9 percent through 2014. All subregions saw marked improvement in total phosphorus and sediment loads to streams between 2005 and 2014. The Eastern Shore subregion improved from a 23-percent 


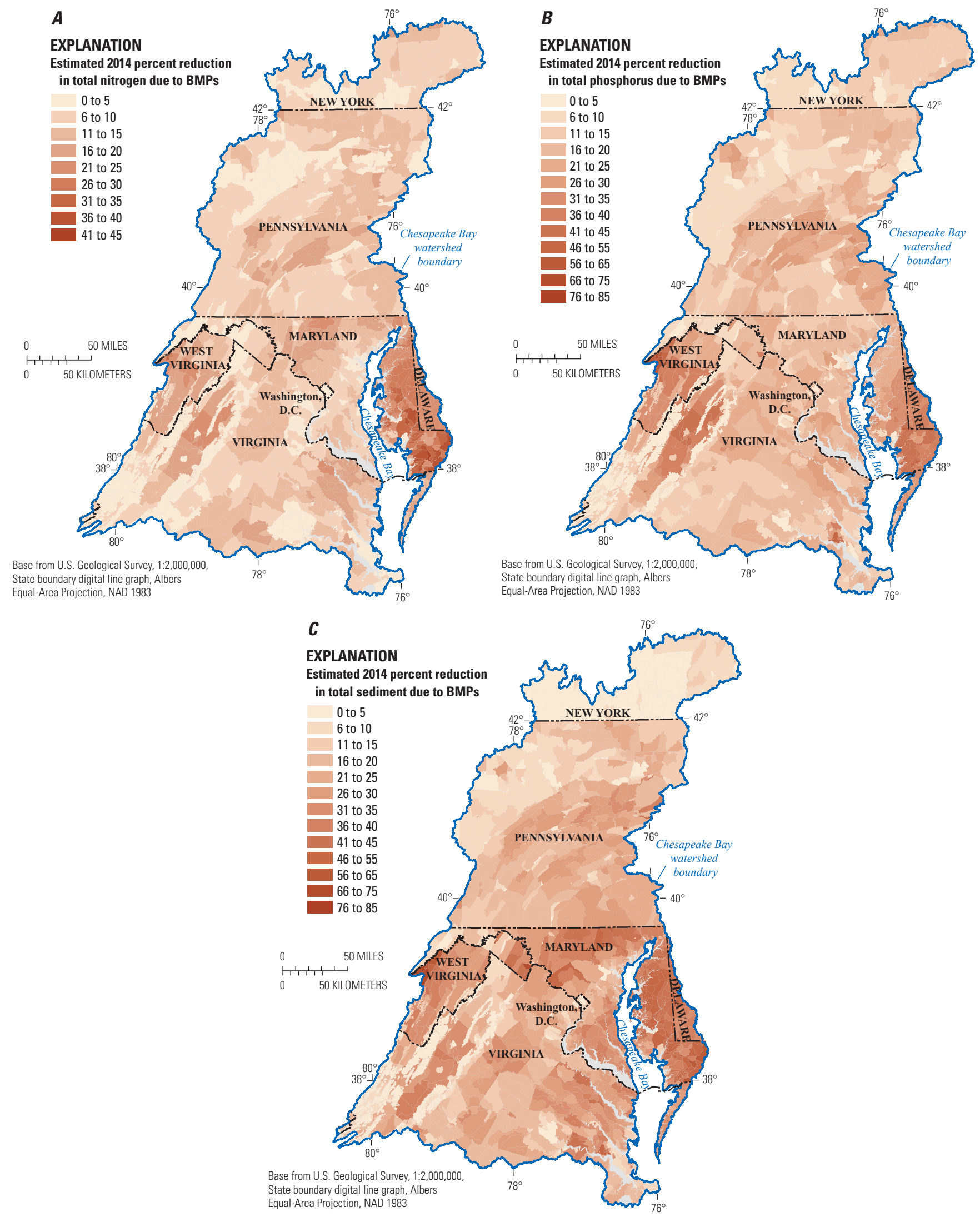

Figure 3. Estimated 2014 percent reduction in $A$, total nitrogen, $B$, total phosphorus, and $C$, total sediment due to Best Management Practices (BMPs) in the Chesapeake Bay watershed. 
$\boldsymbol{A}$

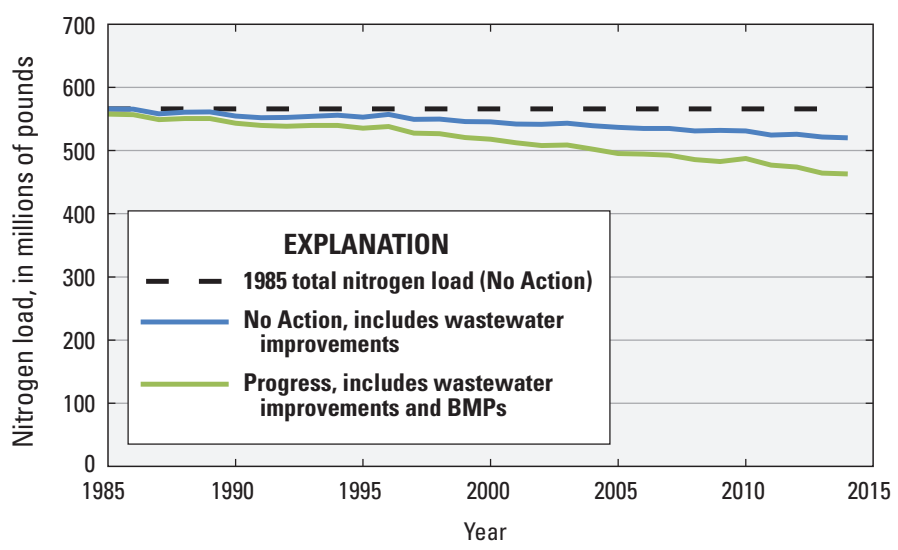

$B$

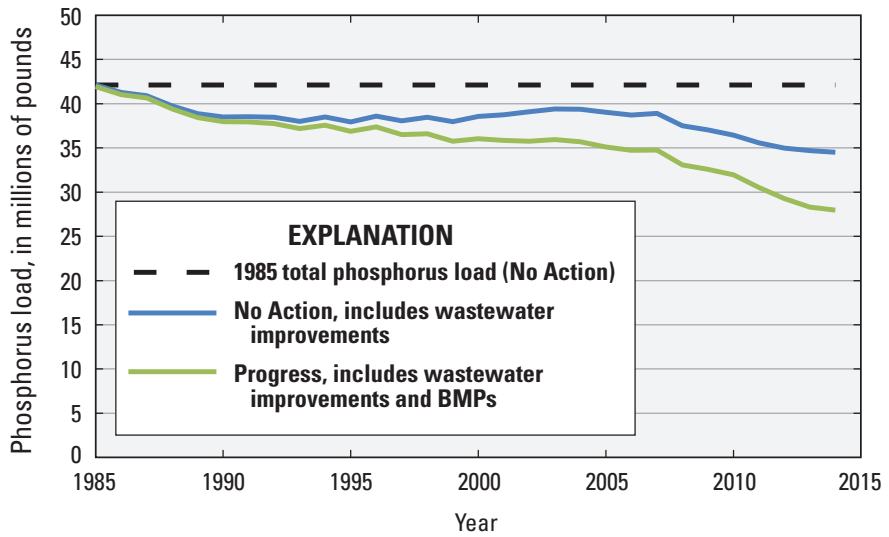

\section{C}

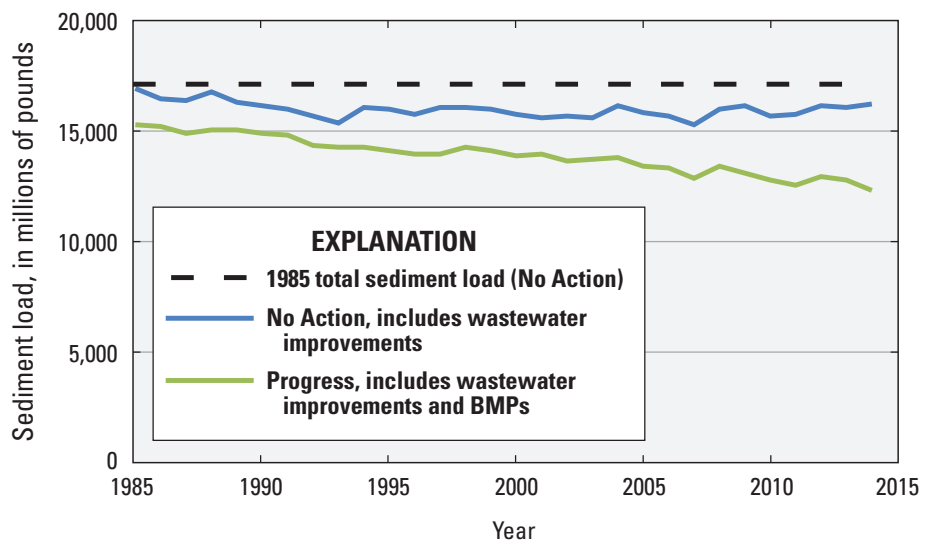

Figure 4. Estimated $A$, total nitrogen load, $B$, total phosphorus load, and $C$, total sediment load from 1985 through 2014 for the No Action scenarios, which do not include Best Management Practices (BMPs), and the Progress scenarios, which do include BMPs.

reduction of total phosphorus to streams through 2005 to a 32-percent reduction through 2014.

Across the entire Chesapeake Bay watershed, BMPs were estimated to have reduced total nitrogen loads to streams by about 49 million pounds by 2014 on the approximately 9 million acres of agricultural land. BMPs on the approximately 5.4 million acres of developed lands were estimated to reduce total nitrogen loads to streams by approximately 7 million pounds in 2014. By 2000, BMPs on agricultural land were estimated to reduce total nitrogen loads to streams by 22 million pounds, whereas BMPs on developed land were estimated to reduce total nitrogen loads by about 4 million pounds (fig. $5 A$ ). Phosphorus loads to streams were estimated to be reduced by 2.2 million pounds by 2000 and 5.2 million pounds by 2014 due to BMPs on agricultural land (fig. 5B). Estimated sediment loads were reduced by nearly 1.6 billion pounds by 2000 and 3.3 billion pounds by 2014 due to BMPs on agricultural land. Developed land BMPs were estimated to reduce phosphorus loads by about 320,000 pounds by 2000 and 1.2 million pounds by 2014 , whereas sediment loads were estimated to be reduced by 260 million pounds by 2000 and 560 million pounds by 2014 (figure 5C). 
Table 4. Estimated reduction of nutrients to streams in Chesapeake Bay watershed subregions due to Best Management Practices (BMPs) in 2005 and 2014 using Progress and No Action Chesapeake Bay Program Phase 5.3.2 model scenarios.

[RIM, River Input Monitoring; ES, Eastern Shore; WS, Western Shore; TN, total nitrogen; TP, total phosphorus; TS, total sediment; \%, percent]

\begin{tabular}{|c|c|c|c|c|c|c|}
\hline Subregion & $\begin{array}{l}\text { TN reduction in } \\
2005 \text { due to BMPs } \\
\text { ( } \% \text { change) }\end{array}$ & $\begin{array}{l}\text { TP reduction in } \\
2005 \text { due to BMPs } \\
\text { ( } \% \text { change) }\end{array}$ & $\begin{array}{l}\text { TS reduction in } \\
2005 \text { due to BMPs } \\
\text { ( } \% \text { change) }\end{array}$ & $\begin{array}{l}\text { TN reduction in } \\
2014 \text { due to BMPs } \\
\text { ( } \% \text { change) }\end{array}$ & $\begin{array}{l}\text { TP reduction in } \\
2014 \text { due to BMPs } \\
\text { (\% change) }\end{array}$ & $\begin{array}{l}\text { TS reduction in } \\
2014 \text { due to BMPs } \\
\text { (\% change) }\end{array}$ \\
\hline Choptank & 16 & 22 & 23 & 22 & 33 & 43 \\
\hline James & 5 & 7 & 14 & 7 & 14 & 25 \\
\hline Non-RIM ES & 18 & 23 & 25 & 25 & 32 & 39 \\
\hline Non-RIM WS & 4 & 6 & 17 & 7 & 15 & 26 \\
\hline Pamunkey & 7 & 9 & 17 & 10 & 14 & 26 \\
\hline Patuxent & 7 & 7 & 24 & 10 & 15 & 29 \\
\hline $\begin{array}{c}\text { Chesapeake Bay } \\
\text { watershed }\end{array}$ & 8 & 10 & 16 & 11 & 19 & 23 \\
\hline
\end{tabular}
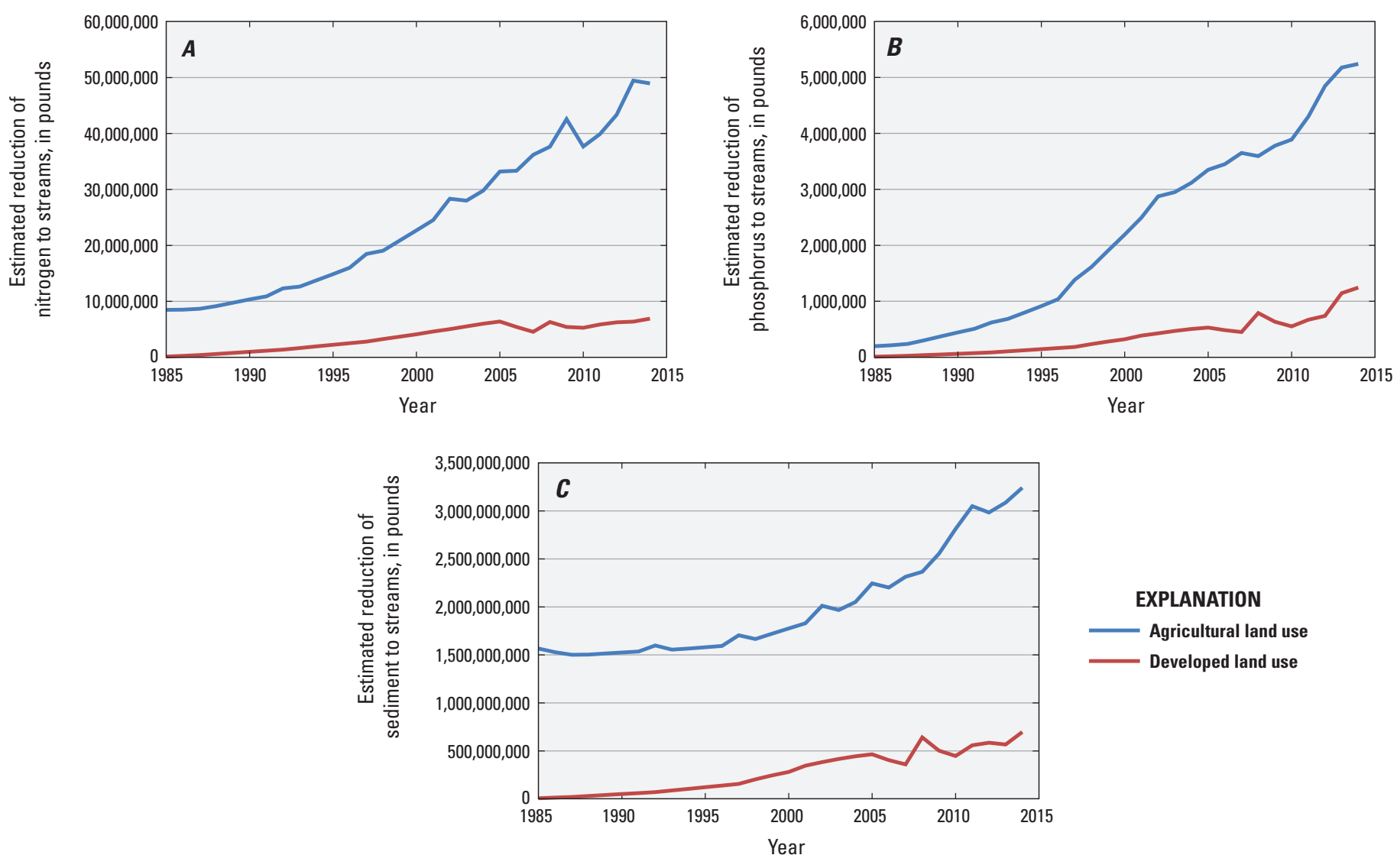

Figure 5. Estimated reduction in $A$, total nitrogen load, $B$, total phosphorus load, and $C$, total sediment load due to Best Management Practices (BMPs) from 1985 through 2014. 


\section{Estimated Effect of Best Management Practices (BMPs) on Nutrient and Sediment Loads}

The BMP isolation scenarios were used to identify the expected reduction in nutrient and sediment loads to streams by various BMP types. The largest estimated reduction in total nitrogen loads on agricultural lands in 2014 can be attributed to the land retirement BMP, with a total reduction of 7.7 million pounds, and the animal waste management system (AWMS) BMP, with an estimated reduction of 7.6 million pounds (fig. 6A). Conservation tillage was estimated to reduce total nitrogen loads by 6.2 million pounds for 2014. The AWMS BMP was estimated to reduce total phosphorus loads to streams by the greatest amount, with a roughly 1.4 million-pound reduction. Other large estimated reductions in phosphorus were attributable to pasture fencing ( 810,000 pounds) and phytase feed additives ( 710,000 pounds) (fig. 6B). The largest estimated reductions in sediment loads were due to conservation tillage ( 1.2 billion pounds), pasture fencing (500 million pounds), and conservation plans (480 million pounds) (fig. 6C).

The average expected effect of each type of agricultural BMP per unit of implementation on nutrient and sediment loads across the Chesapeake Bay watershed also was estimated (table 5). The agricultural BMPs that were estimated to produce the largest reduction in total nitrogen load per acre of implementation were loafing lot management and barnyard runoff controls, with estimated reductions of 110 pounds per acre and 99 pounds per acre of implementation, respectively. The loafing lot management BMP is a practice that is designed to stabilize areas that are intensively used by people, animals, or vehicles by establishing vegetative cover, surfacing with suitable materials, or installing needed structures. Barnyard runoff control includes practices such as control of runoff from barnyards, roof runoff control, and diversion of clean water. These BMPs were not extensively reported across the Chesapeake Bay watershed, so their total estimated effect is not as substantial in comparison to other practices (Devereux and others, 2018). The BMPs that convert agricultural land to other land uses were estimated to reduce total nitrogen by a large amount for each acre of implementation. These BMPs include forest buffers, grass buffers, streamside forest and grass buffers, land retirement, and pasture fencing. These BMPs were estimated to reduce the total nitrogen load to streams from 20 to 56 pounds per acre of implementation. These BMPs were reported to be widespread throughout the watershed, and accounted for 42 percent of the total estimated reduction in nitrogen loads to streams due to agricultural BMPs through 2014. Other agricultural BMPs, such as conservation plans and conservation tillage, were estimated to reduce only a relatively small amount of nitrogen to streams ( 1 and 3 pounds per acre of implementation), but were reported in large enough amounts throughout the watershed to account for almost 22 percent of the total estimated reduction in nitrogen due to agricultural BMPs.

Barnyard runoff control and loafing lot management were estimated to reduce total phosphorus loads by a substantial amount per acre of implementation (19 and 22 pounds per acre), however, the total effect was not estimated to be large due to limited implementation. Pasture fencing and streamside grass buffers also were estimated to be effective at reducing phosphorus loads to streams, with 12 to 13 pounds of phosphorus reduced per acre of implementation. Collectively, they accounted for about 20 percent of the total reduction in phosphorus load due to BMPs on agricultural land by 2014.

The agricultural BMPs with the largest estimated reduction in sediment loads to streams per acre of implementation were streamside grass buffers and pasture fencing at 9,800 and 7,700 pounds per acre, respectively. However, the largest total estimated reduction in sediment loads to streams from agricultural BMPs was attributed to conservation tillage. Conservation tillage accounted for approximately 31 percent of the total estimated reduction in phosphorus to streams by 2014 .

The implementation of certain BMPs that affect nutrients from animal production are reported to the CBP in animal units. Mortality composting was estimated to reduce nitrogen loads to streams by 10 pounds per animal unit, and phosphorus loads by 2 pounds per animal unit. Animal waste management systems were estimated to reduce nitrogen loads to streams by 5 pounds per animal unit, and phosphorus loads by 1 pound per animal unit. Phytase feed additives were estimated to reduce phosphorus loads by 1 pound per animal unit.

Infiltration BMPs were estimated to account for the largest reduction in nitrogen loads to streams from developed land in 2014. Dry ponds and wet ponds also were extensively reported, and accounted for a large proportion of the estimated total nitrogen reduction by 2014 (fig. $7 A$ ). These BMPs also were estimated to have a large effect on phosphorus and sediment loads to streams (figs. $7 B$ and $7 C$ ). Erosion and sediment controls provided the largest total reduction to phosphorus and sediment loads by 2014, with large additional reductions estimated from the abandoned mineland reclamation BMP.

BMPs on developed land vary widely in their effectiveness per unit of implementation (table 6). Bio-Retention was estimated to be the most effective BMP for reducing nutrients and sediment, reducing total nitrogen loads to streams by 81 pounds per acre, total phosphorus loads by 11 pounds per acre, and total sediment by 5,200 pounds per acre of implementation. This BMP was not reported to be implemented substantially across the watershed, and only accounted for about 2.5 percent of the estimated reduction of total nitrogen from BMPs on developed land (Devereux and others, 2018). Dry ponds, wet ponds/wetlands, and infiltration BMPs have a relatively low estimated effectiveness, ranging from 2.3 pounds of nitrogen reduced per acre of implementation to 12.4 pounds per acre, but were reported to be implemented extensively throughout the watershed. They accounted for 49 percent of the reduction in nitrogen loads from developed 

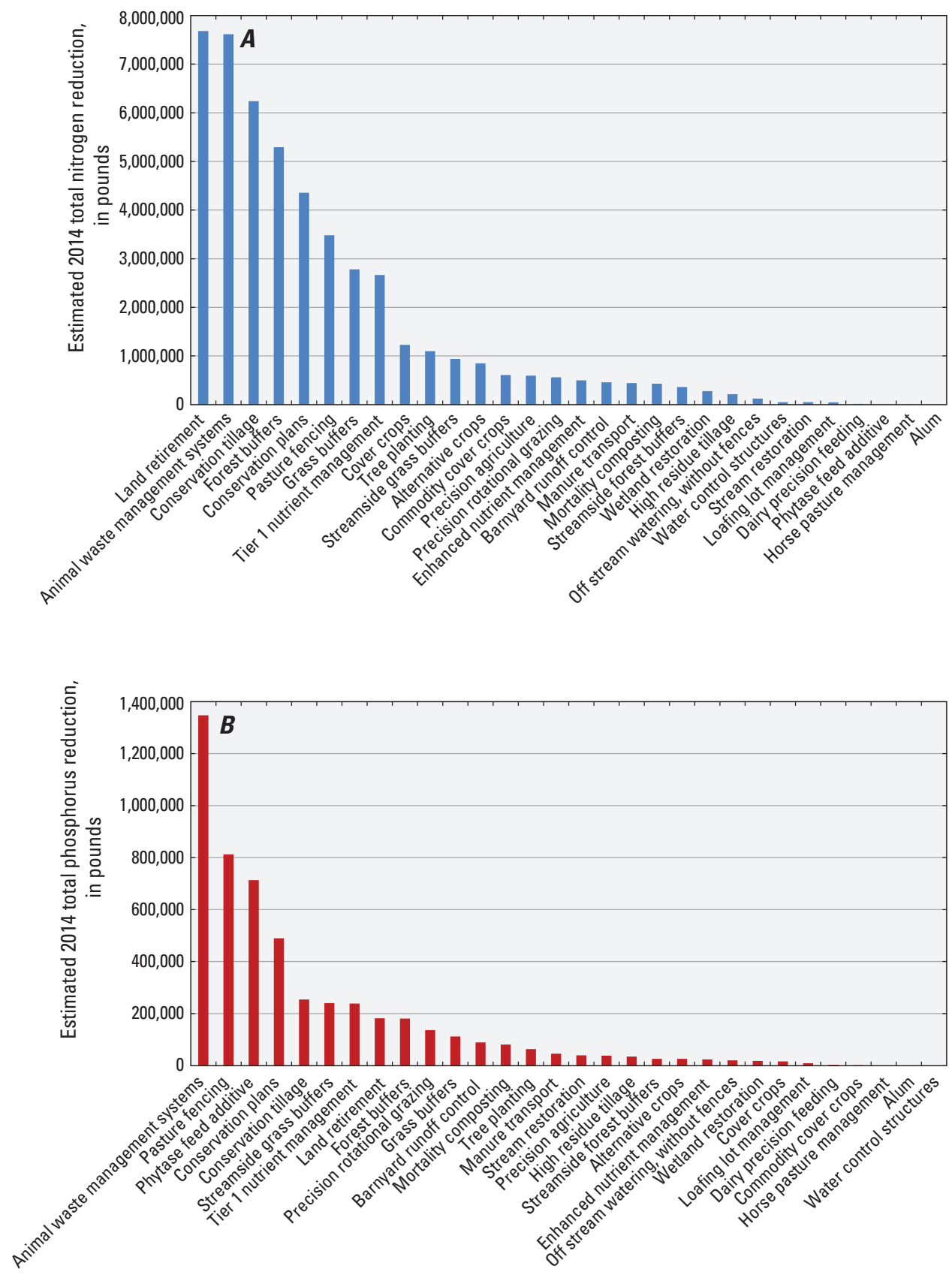

Figure 6. Estimated $A$, total nitrogen reduction, $B$, total phosphorus reduction, and $C$, total sediment reduction by Best Management Practice (BMP) category on agricultural lands in 2014. 


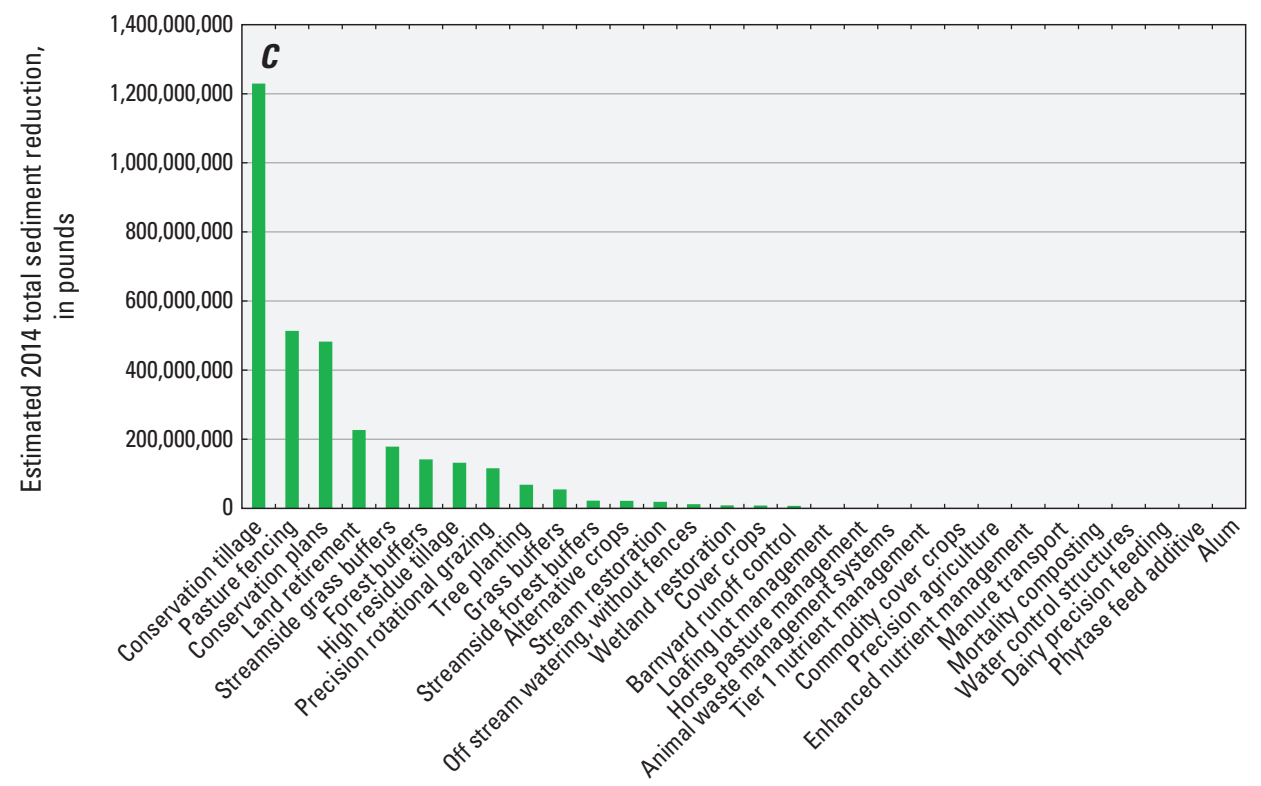

Figure 6. Estimated $A$, total nitrogen reduction, $B$, total phosphorus reduction, and $C$, total sediment reduction by Best Management Practice (BMP) category on agricultural lands in 2014. - Continued

land to streams, 48 percent of the phosphorus reduction, and 36 percent of the sediment reduction.

In 1985, the conservation tillage BMP accounted for nearly all of the estimated reduction in total nitrogen ( 95 percent), phosphorus ( 87 percent), and sediment (98 percent) loads due to BMPs on agricultural land in the Chesapeake Bay watershed (figs. $8 A, 8 B$, and $8 C$ ). By the year 2000, conservation tillage accounted for 30 percent of the estimated nitrogen reduction, 9 percent of the estimated phosphorus reduction, and 68 percent of the estimated sediment reduction. By 2014, conservation tillage accounted for just 13 percent of the total estimated nitrogen reduction, 5 percent of the estimated phosphorus reduction, and 38 percent of the estimated reduction in sediment loads. After the year 1997, a wider variety of agricultural BMPs were reported in greater numbers. Land-use change type BMPs became more prevalent across the watershed. In 2014, land retirement, pasture fencing, grass and forest buffers, streamside grass and forest buffers, and tree plantings accounted for 44 percent of the estimated reduction in nitrogen load to streams, 31 percent of the estimated reduction in phosphorus load to streams, 37 percent of the estimated reduction in sediment load to streams.

The infiltration, dry pond, and wet pond BMPs accounted for the majority of estimated total nitrogen reductions to streams from 1985 to 2014 due to BMPs on developed land (fig. 9A). Prior to 2005, nearly all of the reduction in nitrogen was predicted to come from these three BMPs. The Forest Conservation Act (Department of Legislative Services, Office of Policy Analysis, 2017), which is reported in Maryland, has accounted for a growing proportion of the estimated nitrogen reduction from 2006 through 2014. Stormwater management BMPs are estimated to have had a slightly increased total effect over the study period. By 2014, they were estimated to have had a similar overall effect as wet ponds. Sharp increases in estimated phosphorus and sediment reductions after 2005 were driven by the erosion and sediment controls and abandoned mineland reclamation BMPs (figs. $9 B$ and $9 C$ ). Some developed land BMPs fluctuated greatly from year to year. This may have been due to changing reporting standards or the nature of their implementation. Some BMPs are dependent on continual investment to remain operational, which may not always be possible. 
Table 5. Agricultural land Best Management Practice (BMP) estimated mass reduction per unit of implementation in the Chesapeake Bay watershed.

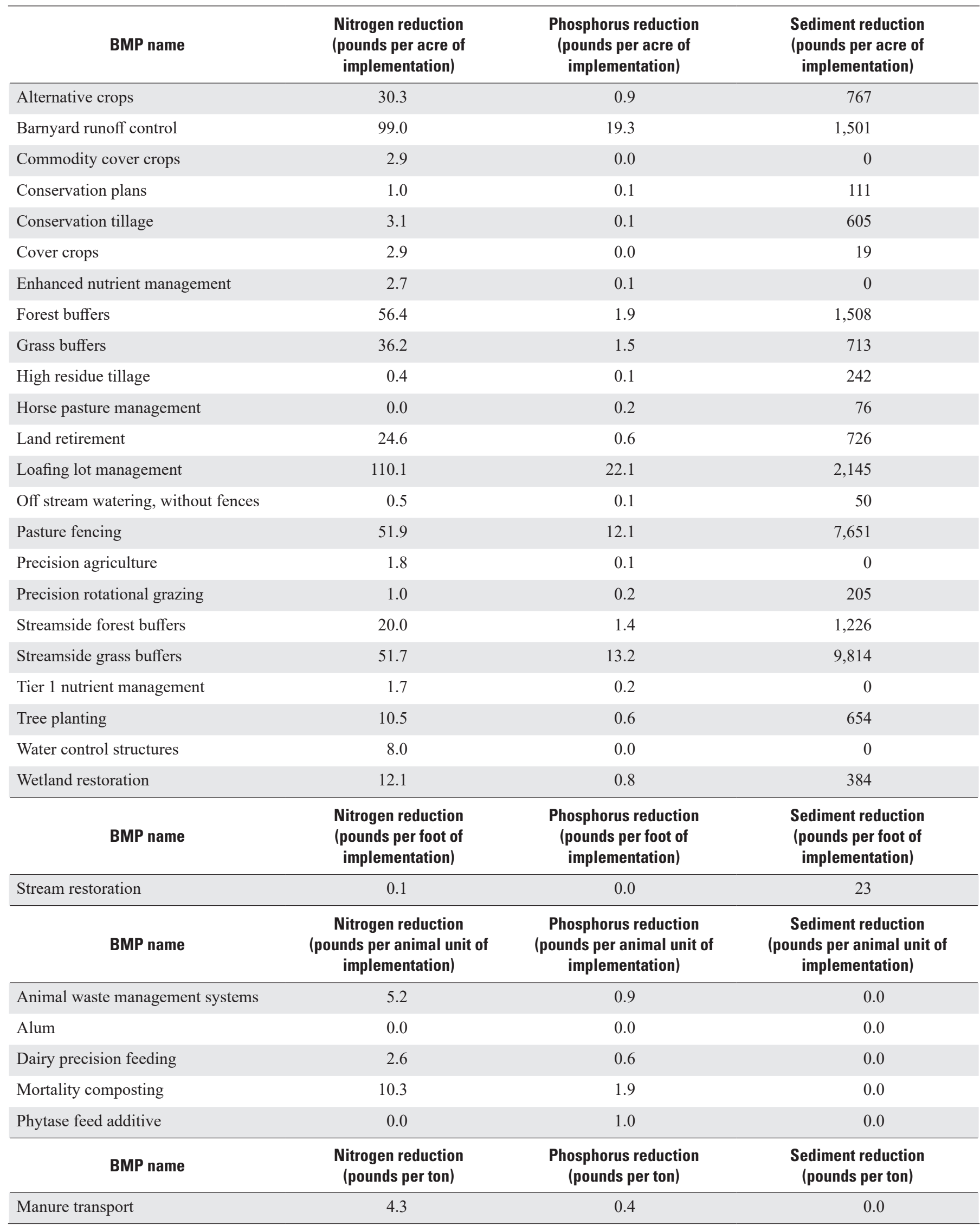



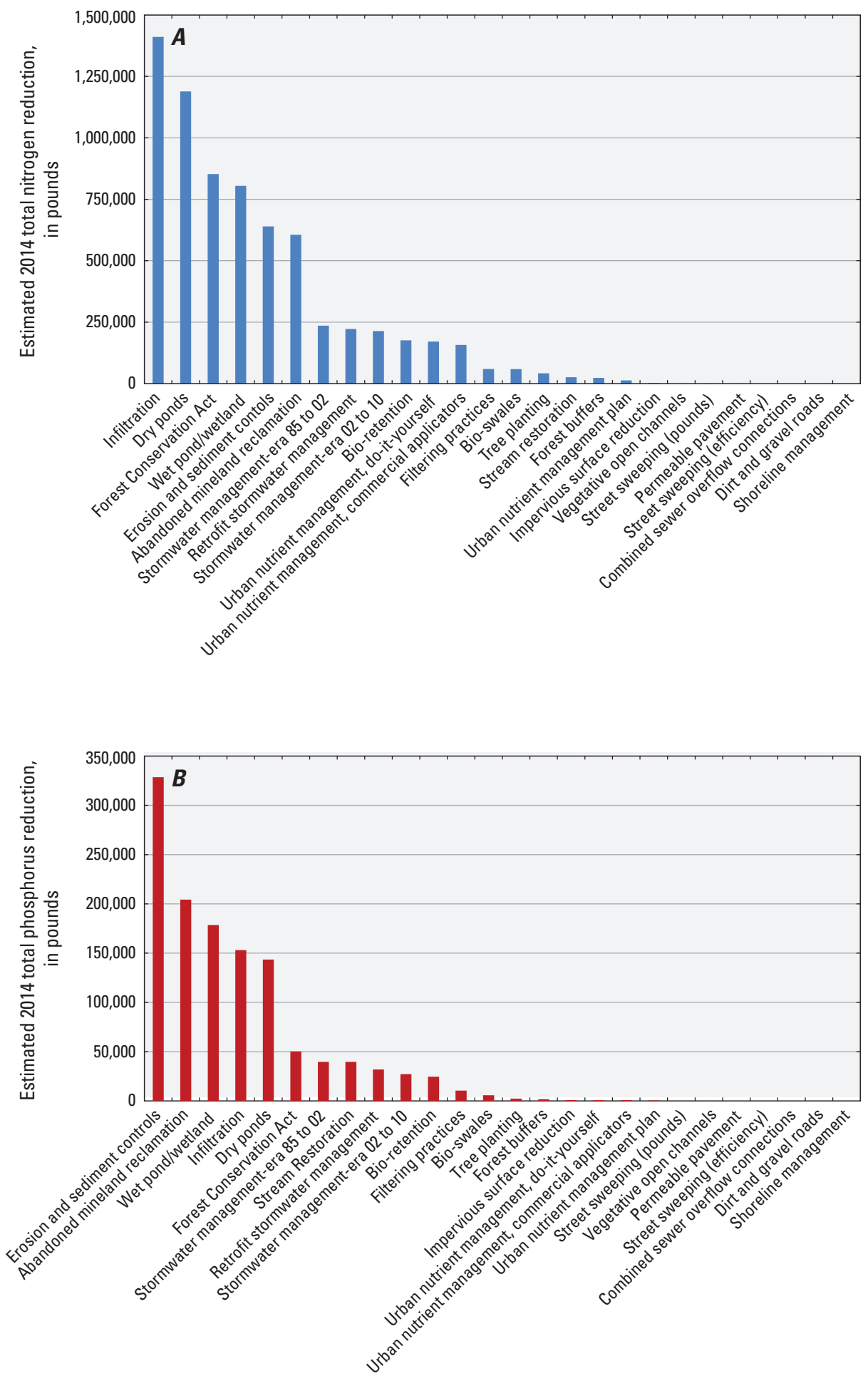

Figure 7. Estimated $A$, total nitrogen reduction, $B$, total phosphorus reduction, and $C$, total sediment reduction by Best Management Practice (BMP) category on developed lands in 2014. 


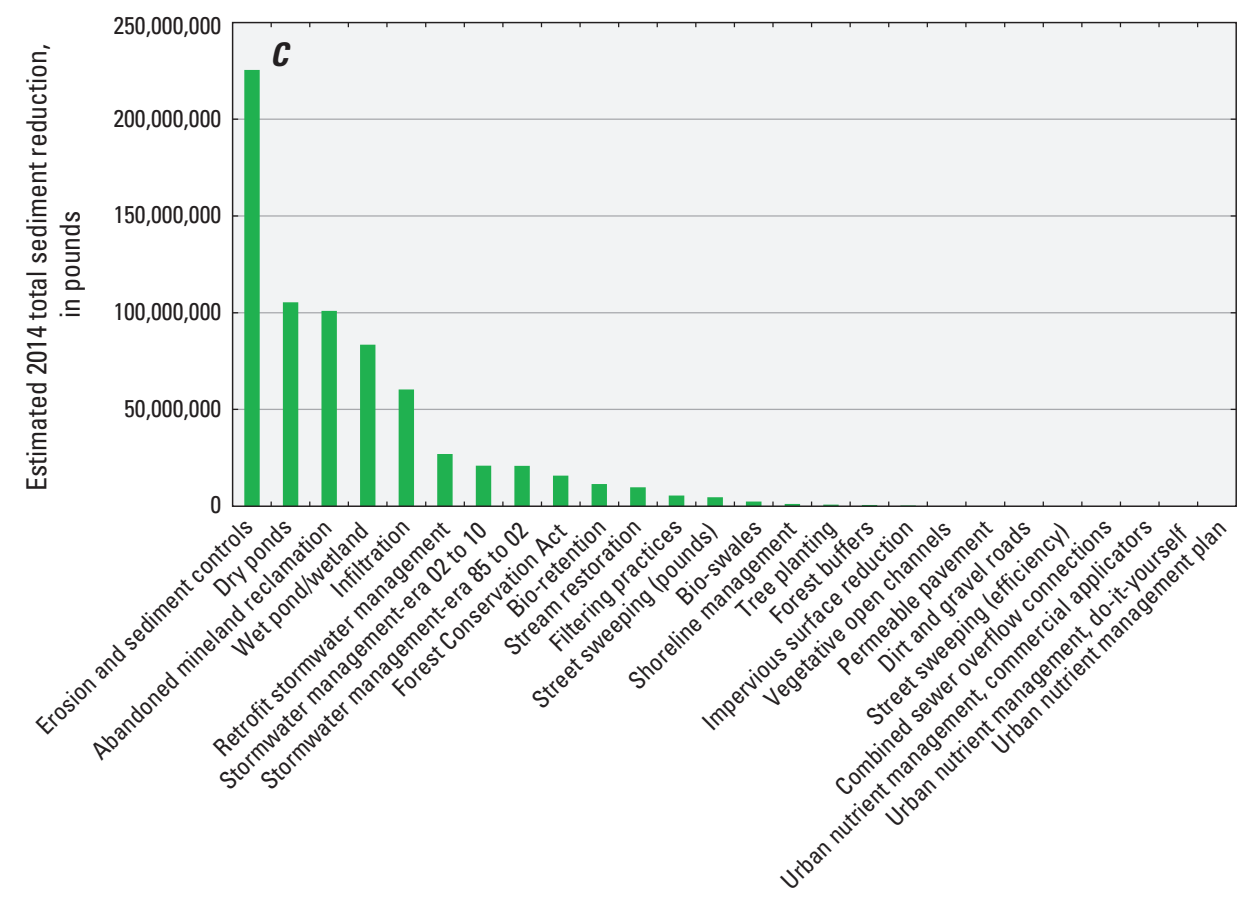

Figure 7. Estimated $A$, total nitrogen reduction, $B$, total phosphorus reduction, and $C$, total sediment reduction by Best Management Practice (BMP) category on developed lands in 2014.-Continued 
Table 6. Developed land Best Management Practice (BMP) estimated mass reduction per unit of implementation in the Chesapeake Bay watershed.

\begin{tabular}{|c|c|c|c|}
\hline BMP name & $\begin{array}{l}\text { Nitrogen reduction } \\
\text { (pounds per acre of } \\
\text { implementation) }\end{array}$ & $\begin{array}{l}\text { Phosphorus reduction } \\
\text { (pounds per acre of } \\
\text { implementation) }\end{array}$ & $\begin{array}{l}\text { Sediment reduction } \\
\text { (pounds per acre of } \\
\text { implementation) }\end{array}$ \\
\hline Bio-retention & 80.8 & 11.3 & 5,242 \\
\hline Combined sewer overflow connections & 0.0 & 0.0 & 0 \\
\hline Dry ponds & 1.3 & 0.2 & 118 \\
\hline Erosion and sediment controls & 7.9 & 4.1 & 2,801 \\
\hline Impervious surface reduction & 3.3 & 1.5 & 590 \\
\hline Infiltration & 12.4 & 1.3 & 528 \\
\hline Permeable pavement & 2.6 & 0.4 & 174 \\
\hline Retrofit stormwater management & 2.7 & 0.4 & 332 \\
\hline Stormwater management-era 02 to 10 & 2.7 & 0.3 & 266 \\
\hline Stormwater management-era 85 to 02 & 1.8 & 0.3 & 160 \\
\hline Urban nutrient management plan & 0.7 & 0.0 & 0 \\
\hline Vegetative open channels & 3.4 & 0.3 & 186 \\
\hline \multirow[t]{2}{*}{ Wet pond/wetland } & 2.3 & 0.5 & 242 \\
\hline & $\begin{array}{l}\text { Nitrogen reduction } \\
\text { (pounds per pound of } \\
\text { implementation) }\end{array}$ & $\begin{array}{l}\text { Phosphorus reduction } \\
\text { (pounds per pound of } \\
\text { implementation) }\end{array}$ & $\begin{array}{l}\text { Sediment reduction } \\
\text { (pounds per pound of } \\
\text { implementation) }\end{array}$ \\
\hline \multirow[t]{2}{*}{ Street sweeping (pounds) } & 0.0 & 0.0 & 0.9 \\
\hline & $\begin{array}{l}\text { Nitrogen reduction } \\
\text { (pounds per foot of } \\
\text { implementation) }\end{array}$ & $\begin{array}{l}\text { Phosphorus reduction } \\
\text { (pounds per foot of } \\
\text { implementation) }\end{array}$ & $\begin{array}{l}\text { Sediment reduction } \\
\text { (pounds per foot } \\
\text { implementation) }\end{array}$ \\
\hline Dirt and gravel roads & 0.0 & 0.0 & 3 \\
\hline Shoreline management & 0.0 & 0.0 & 46 \\
\hline Stream restoration & 0.1 & 0.1 & 22 \\
\hline
\end{tabular}



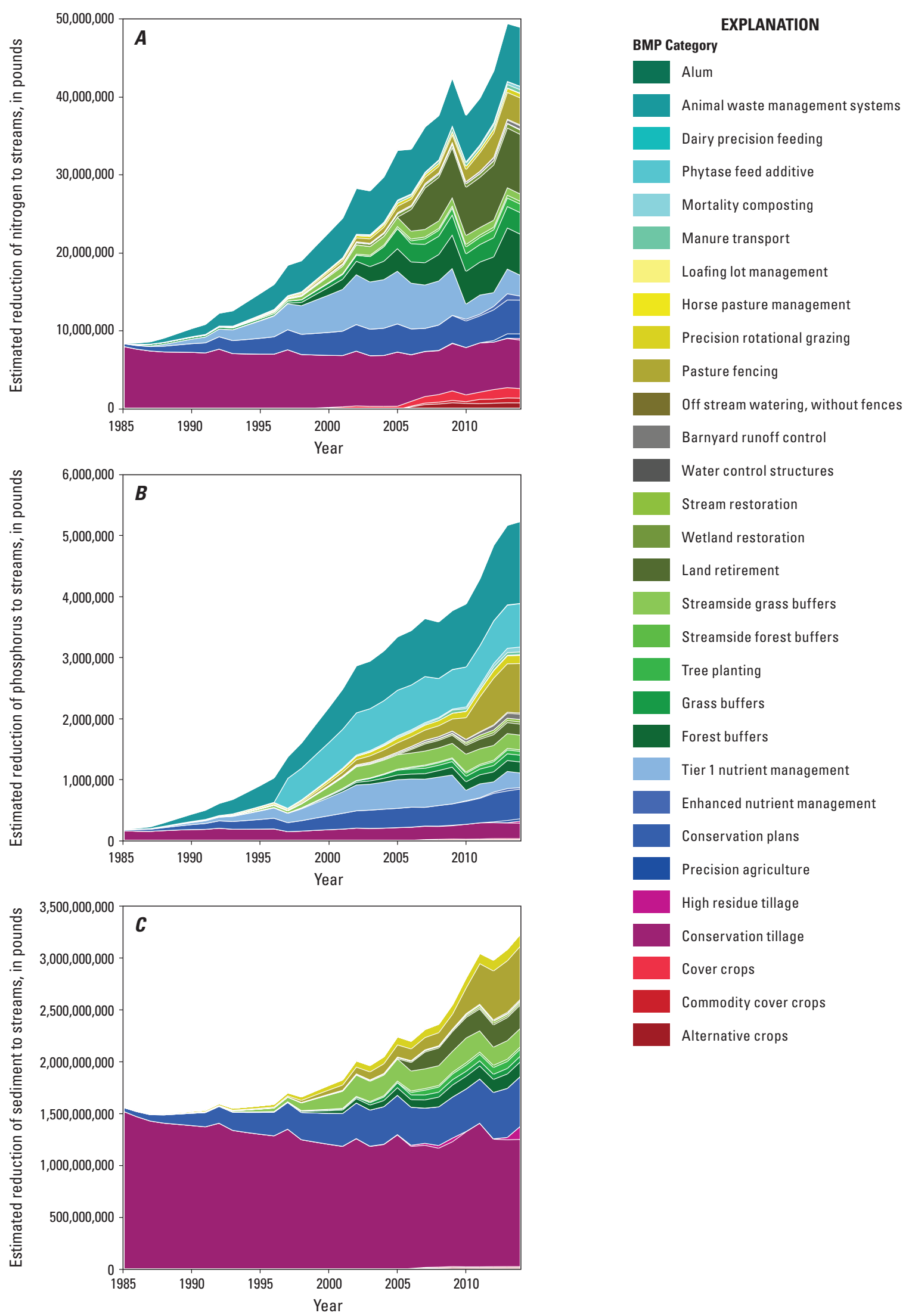

Figure 8. Estimated $A$, total nitrogen reduction, $B$, total phosphorus reduction, and $C$, total sediment reduction from agricultural Best Management Practices (BMPs) from 1985 through 2014 in the Chesapeake Bay watershed. 

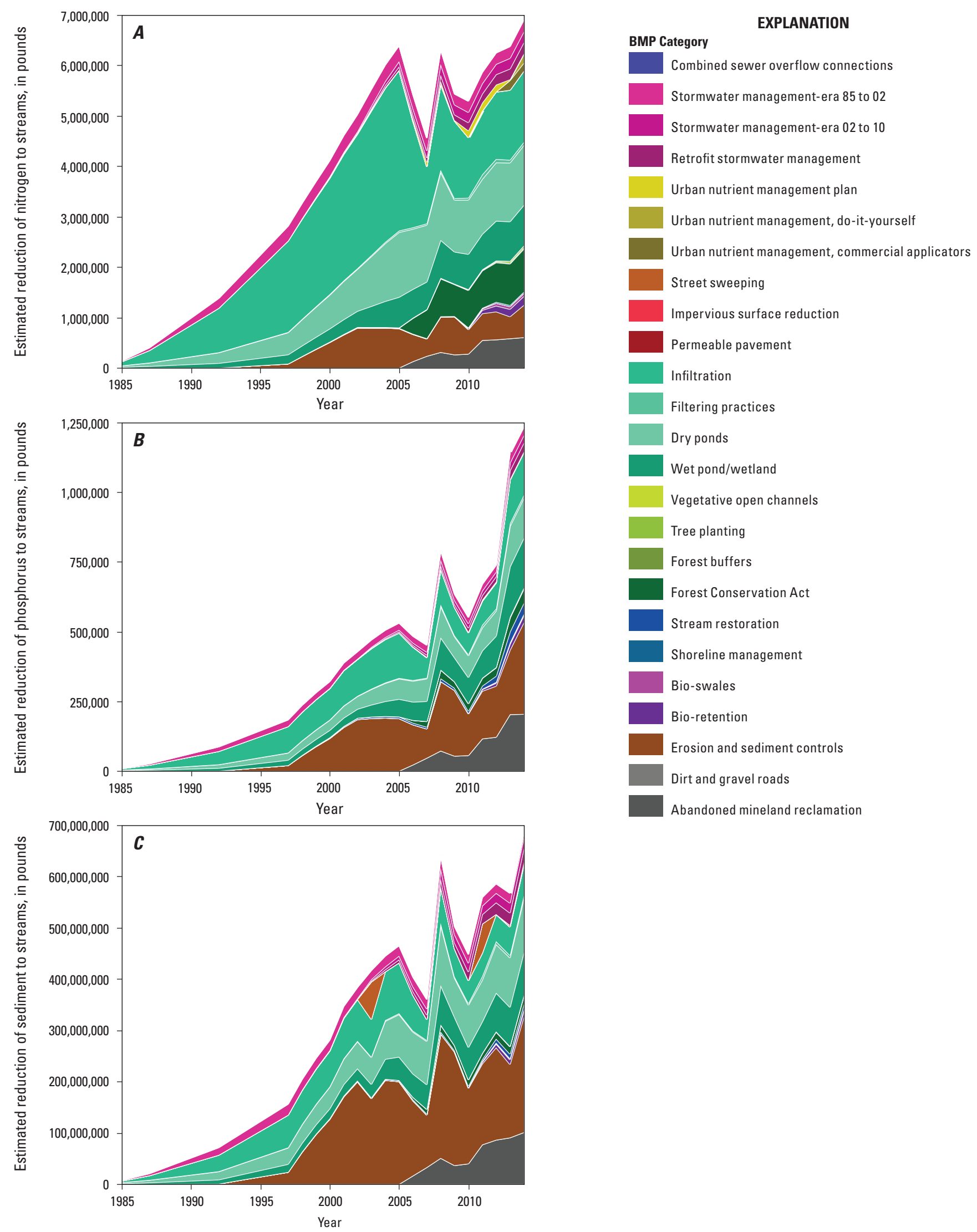

Figure 9. Estimated $A$, total nitrogen reduction, $B$, total phosphorus reduction, and $C$, total sediment reduction from developed land Best Management Practices (BMPs) from 1985 through 2014 in the Chesapeake Bay watershed. 


\section{Summary and Conclusions}

The U.S. Geological Survey (USGS), in conjunction with the Chesapeake Bay Program (CBP), undertook this study to improve the understanding of the effectiveness of waterquality management actions on nitrogen, phosphorus, and sediment loads to streams in the Chesapeake Bay watershed. Estimates of Best Management Practice (BMP) effectiveness were not extensively documented at the regional scale in the study area. Information on the spatial and temporal patterns of BMP implementation can provide context to current conditions as well as assist in understanding trends in water-quality loads. The CBP Partnership Phase 5.3.2 Watershed Model was used to evaluate a set of scenarios in order to investigate spatial and temporal patterns of BMP implementation in the Chesapeake Bay watershed. The CBP also provided reported amounts of various types of BMP implementation on agricultural and developed land. Year to year changes in reported BMP implementation may partially reflect changing reporting standards and the revision of historical records in addition to actual changes in BMP implementation. An analysis of model results was performed in order to estimate the expected effectiveness of BMPs at mitigating nutrient and sediment loads throughout the watershed. The total expected effect of different types of BMPs on nitrogen, phosphorus, and sediment were estimated as well as the expected effect per unit of BMP implementation.

Conservation plans, conservation tillage, and tier 1 nutrient management plans were identified as the BMPs with the most reported acres of implementation in the Chesapeake Bay watershed in 2014. A measure of BMP implementation intensity was defined as acres of BMP implementation per available land use. Spatial patterns of BMP implementation can be associated with different agricultural practices throughout the watershed. Areas with large amounts of animal production, such as the Potomac subregion, were found to have large amounts of related animal type BMPs, such as pasture fencing and animal waste management systems (AWMSs). In general, areas of high crop production tended to have large amounts of cover crops and conservation tillage. Additionally, each jurisdiction in the Chesapeake Bay watershed (consisting of New York, Maryland, Pennsylvania, Delaware, West Virginia, Virginia, and the District of Columbia) tended to focus on certain types of BMPs. Maryland had a higher intensity of reported cover crops and conservation tillage BMPs than other areas of the watershed. Pennsylvania had a lower intensity of BMPs reported on cropland in comparison to other jurisdictions. Virginia had a higher intensity of animal type BMPs.

The amount of agricultural BMPs reported as acres in the Chesapeake Bay watershed increased from 1985 to 2014. Developed land BMPs were only reported in small numbers in 1985, but increased substantially from 2000 to 2014 . Conservation tillage constituted the majority of reported agricultural BMP implementation in 1985 and increased slightly by 2014 but decreased from 88 percent to 18 percent of the proportion of the total reported agricultural BMP implementation during the same time period as more alternative BMP types became available and were reported. After the year 2000, a larger proportion of agricultural BMPs consisted of land-use change type BMPs, including land retirement, pasture fencing, grass buffers, and forest buffers.

By 2014, BMPs were estimated to have reduced total nitrogen loads to streams by approximately 49 million pounds on agricultural land and 7 million pounds on developed land.

Agricultural BMPs were estimated to reduce phosphorus loads to streams by 5 million pounds whereas BMPs on developed lands were expected to reduce phosphorus loads by about 1 million pounds. Reductions in sediment loads due to BMPs were estimated at 3.3 billion pounds for agricultural BMPs and 560 million pounds for developed land BMPs.

The largest estimated reduction in total nitrogen on agricultural lands by 2014 was attributed to land retirement, AWMSs, and conservation tillage. AWMSs were estimated to reduce total phosphorus loads to streams by the largest amount, followed by pasture fencing and phytase feed. Other agricultural BMPs had a marginal effect on phosphorus loads by comparison. Conservation tillage, conservation plans, and pasture fencing were estimated to have the greatest total effects on sediment loads to streams.

Loafing lot management and barnyard runoff controls had the highest estimated reduction in nitrogen and phosphorus per acre of implementation, but were not widely reported across the Chesapeake Bay watershed. Land-use conversion BMPs, such as forest buffers, grass buffers, streamside forest and grass buffers, land retirement, and pasture fencing were estimated to reduce the total nitrogen load to streams from 20 to 56 pounds per acre of implementation. These BMPs accounted for 42 percent of the total estimated reduction in nitrogen loads to streams due to agricultural BMPs by 2014. Conservation plans and conservation tillage were estimated to reduce only 1 and 3 pounds per acre of implementation, respectively, but accounted for 22 percent of the total estimated reduction in nitrogen due to agricultural BMPs. Pasture fencing and streamside grass buffers were estimated to be effective at reducing phosphorus loads to streams with 12 and 13 pounds of phosphorus reduced per acre of implementation, and these BMPs accounted for about 20 percent of the total reduction in phosphorus load on agricultural land by 2014. Conservation tillage accounted for the largest total estimated reduction in sediment loads to streams.

Bio-retention was estimated to be the most effective BMP for reducing nutrients and sediment on developed land, but this BMP is not frequently used or reported in the Chesapeake Bay watershed. Although dry ponds, wet ponds and constructed wetlands, and infiltration BMPs have a relatively low estimated effectiveness, they accounted for 49 percent of the total reduction in nitrogen loads to streams due to BMPs, 48 percent of the phosphorus load reduction, and 36 percent of the sediment load reduction.

Conservation tillage accounted for nearly all of the estimated reduction in total nitrogen, phosphorus, and sediment loads due to BMPs on agricultural land in the Chesapeake 
Bay watershed in 1985. Although the total estimated reduction in nutrients and sediment from this BMP did not change significantly by 2014 , conservation tillage accounted for just 13 percent of the total estimated nitrogen reduction, 5 percent of the total estimated phosphorus reduction, and 38 percent of the total estimated sediment load reduction as a wider variety of agricultural BMPs were reported. These included land-use change type BMPs, such as land retirement, pasture fencing, grass and forest buffers, streamside grass and forest buffers, and tree plantings.

The largest reductions in nitrogen, phosphorus, and sediment to streams by 2014 were predicted on the Eastern Shore of the Chesapeake Bay and in the Potomac subregion. A large amount of reported implementation of conservation tillage, cover crops, AWMSs, and conservation plans on the Eastern Shore were responsible for large estimated reductions in nutrient and sediment loads to streams. In the Potomac subregion, extensive implementation of pasture fencing was estimated to reduce nutrient loads in addition to the implementation of a variety of other BMPs to pasture and cropland.

\section{References Cited}

Department of Legislative Services, Office of Policy Analysis, 2017, Forest Conservation Act and Other Forester Programs in Maryland, accessed June 11, 2018, at http://dls.maryland. gov/pubs/prod/NatRes/Forest-Conservation-Act-and-OtherForestry-Programs-in-Maryland.pdf.

Devereux, O.H., Sekellick A.J., and LaMotte, A.E., 2018, Estimated effect of best management practice implementation on water quality in the Chesapeake Bay watershed from 1985 to 2014: U.S. Geological Survey data release, https:// doi.org/10.5066/P9OVU9PX.

Hively, W.D., Devereux, O.H., and Claggett, P., 2013, Integrating Federal and State data records to report progress in establishing agricultural conservation practices on Chesapeake Bay farms: U.S. Geological Survey Open-File Report 2013-1287, 36 p., accessed August 21, 2018, at https://doi. org/10.3133/ofr20131287.

Liu, Y., Engel, B.A., Flanagan, D.C., Gitau, M.W., McMillan, S.K., and Chaubey, I., 2017, A review on effectiveness of best management practices in improving hydrology and water quality: Needs and opportunities: Science of the Total Environment, v. 601-602, p. 580-593, accessed August 21, 2018, at http://doi.org/10.1016/j.scitotenv.2017.05.212.

Phillips, S.W., ed., 2007, Synthesis of U.S. Geological Survey science for the Chesapeake Bay ecosystem and implications for environmental management: U.S. Geological Survey Circular 1316, 63 p., accessed August 21, 2018, at https:// pubs.usgs.gov/circ/circ1316/.
U.S. Environmental Protection Agency, 2010a, Chesapeake Bay TMDL Executive Summary, accessed January 11, 2017, at https:/www.epa.gov/sites/production/files/2014-12/ documents/bay_tmdl_executive_summary_final_12.29.10_ final_1.pdf.

U.S. Environmental Protection Agency, 2010b, Chesapeake Bay Phase 5.3.0 Community Watershed Model: Annapolis, Maryland, U.S. Environmental Protection Agency, Chesapeake Bay Program Office, EPA 903S10002 - CBP/ TRS-303-10, December 2010, accessed January 11, 2017, at http://ches.communitymodeling.org/models/CBPhase5/ documentation.php.

Wastewater Technical Workgroup (WTWG), 2013, Minutes of the Chesapeake Bay Program Watershed Technical Workgroup Conference Call, July 8, 2013, accessed January 11, 2017, at https://www.chesapeakebay.net/channel_ files/19141/wtwg_070813_minutes_final_draft.pdf. 
For additional information, contact: Director, MD-DE-DC Water Science Center U.S. Geological Survey 5522 Research Park Drive

Baltimore, MD 21228

or visit our website at: http://md.water.usgs.gov/

Publishing support provided by West Trenton Publishing Service Center 


\section{蛋}

